\title{
Multiproperty modeling for a set of binary systems. Evaluation of a model to correlate simultaneously several mixing properties of methyl ethanoate + alkanes and new experimental data
}

\author{
Luís Fernández ${ }^{\mathrm{a}}$, Estefanía Pérez ${ }^{\mathrm{a}}$, Juan Ortega ${ }^{\mathrm{a}, *}$, José Canosa ${ }^{\mathrm{b}}$, Jaime Wisniak ${ }^{\mathrm{c}}$ \\ a Laboratorio de Termodinámica y Fisicoquímica de Fluidos, 35071-Parque Científico-Tecnológico, Universidad de Las Palmas de Gran Canaria, Canary Islands, Spain \\ b Departamento de Ingeniería Química, Universidad de Vigo, Spain \\ ${ }^{\mathrm{C}}$ Department of Chemical Engineering, Ben-Gurion, University of the Negev, Beer-Sheva 84105, Israel
}

\section{A R T I C L E I N F O}

\section{Article history:}

Received 26 September 2012

Received in revised form

24 December 2012

Accepted 29 December 2012

Available online 8 January 2013

\section{Keywords:}

Multiproperty correlation

Phase equilibria

Mixing properties

Methyl ethanoate

Alkane

\begin{abstract}
A B S T R A C T
This work makes a theoretical-experimental contribution to the study of ester and alkane solutions. Experimental data of isobaric vapor-liquid equilibria (VLE) are presented at $101.3 \mathrm{kPa}$ for binary systems of methyl ethanoate with six alkanes (from $C_{5}$ to $C_{10}$ ), and of volumes and mixing enthalpies, $v^{\mathrm{E}}$ and $h^{\mathrm{E}}$. An interpretation of the behavior and a verification of structural models proposed previously by the same group are also given. For the treatment of thermodynamic data a polynomial model is proposed to obtain a simultaneous correlation of different properties available for a same system. Liquid-liquid equilibrium (LLE) data at low pressure are also used and $c_{\mathrm{p}}^{\mathrm{E}}$ values, taken from literature, to perform the correlations described, generating a working procedure which is started on LLE data. The properties used for correlating are obtained in very different working conditions making it difficult to obtain a single correlation. However, the procedure followed produces good multiproperty correlations for each of the systems. An extended version of the NRTL model is also used with the purpose of comparing the efficacy of the method and model proposed, and produces acceptable results for the isobaric and isothermal VLE equilibrium but not for the LLE. Specifically, the model does not take into account the variation in $h^{\mathrm{E}}=\varphi(T)$, as it does not reproduce the $c_{\mathrm{p}}^{\mathrm{E}}$. Estimates of the same properties made with the UNIFAC group contribution method are comparable to those obtained with the correlative NRTL method.
\end{abstract}

(c) 2013 Elsevier B.V. All rights reserved.

\section{Introduction}

In this work, experimental and theoretical contributions to thermodynamic properties, liquid-liquid equilibrium (LLE) and vapor-liquid equilibrium (VLE) are presented. First, to justify our work in relation to its experimental contributions, several years ago our research group systematically carried out studies into alkyl alkanoate solutions with different organic solvents, especially with alkanols, and published a large amount of data on excess properties [1-3] and isobaric VLE [4-10]. More recently, we started to work with mixtures of esters and hydrocarbons $[11,12]$ as primary systems of those above mentioned. Further interest into studies on esters, in addition to their presence in biofuels, is associated with their presence in many industrial processes, and their use as reagents or additives (in the food industry), forming part of solutions with other organic compounds. More detailed knowledge of the primary systems of esters and alkanes provides valuable

\footnotetext{
* Corresponding author. Tel.: +34 928459548.

E-mail address: jortega@dip.ulpgc.es (J. Ortega).
}

information that helps us to understand better the systems constituting the applications cited above. The limited experimental data available for these primary systems explain why the predictive/correlative methods do not reach the level of precision currently required in engineering designs.

For this work, isobaric VLE were experimentally determined at $101.32 \mathrm{kPa}$ for six binary systems of methyl ethanoate $\mathrm{CH}_{3} \mathrm{COOCH}_{3}$ with one of the six saturated hydrocarbons $C_{5}$ to $C_{10}$, because no isobaric studies were found in the literature with the exception of $\mathrm{CH}_{3} \mathrm{COOCH}_{3}+\mathrm{C}_{7} \mathrm{H}_{16}$ system [13]. Many of the mixtures considered here have also been studied previously using some mixing properties, such as iso- $T$ VLE [14,15], LLE [16,17], $v^{\mathrm{E}}, h^{\mathrm{E}}[13,14,18-38]$ and $c_{\mathrm{p}}^{\mathrm{E}}$ [29]. Table 1 shows a summary of the properties measured by other authors, although only some of them are available for our study, such as is noted in Table 1 and explained in the following sections. New measurements are reported for $v^{\mathrm{E}}$ and $h^{\mathrm{E}}$ at several temperatures.

Estimates are given for different properties for the set of binaries reported in this study using the UNIFAC group contribution method [39]. As background information, application of this method to the corresponding binaries with ethyl ethanoate from a previous work 
Table 1

Thermodynamic properties used in the modelization procedure of the binaries methyl ethanoate + alkanes, references and operating conditions.

\begin{tabular}{|c|c|c|c|c|c|c|c|c|}
\hline $\mathrm{C}_{2} \mathrm{H}_{6} \mathrm{O}_{2}+$ & Property & $T(\mathrm{~K})$ & $p(\mathrm{kPa})$ & Ref. & Property & $T(\mathrm{~K})$ & $p(\mathrm{kPa})$ & Ref. \\
\hline \multirow[t]{5}{*}{$\mathrm{C}_{5} \mathrm{H}_{12}$} & VLE & - & 101 & This work & $v^{\mathrm{E}}$ & 291 & 101 & This work \\
\hline & VLE & 298 & - & {$[14,15]$} & & 298 & 101 & This work \\
\hline & LLE & - & 0.3 & [16] & & 298 & 101 & {$[14]^{a},[24]^{a}$} \\
\hline & $h^{\mathrm{E}}$ & 298 & 101 & {$[14]^{\mathrm{a}},[25]$} & & & & \\
\hline & & 291 & 101 & This work & & & & \\
\hline \multirow[t]{9}{*}{$\mathrm{C}_{6} \mathrm{H}_{14}$} & VLE & - & 101 & This work & $v^{\mathrm{E}}$ & 291 & 101 & This work \\
\hline & LLE & - & 0.4 & [16] & & 298 & 101 & This work \\
\hline & $h^{\mathrm{E}}$ & 291 & 101 & This work & & 318 & 101 & This work \\
\hline & & 318 & 101 & This work & & 298 & 101 & {$[19]^{a},[26]^{a},[28]^{a},[32]^{a}$} \\
\hline & & 298 & 101 & {$[19],[33]^{\mathrm{a}},[34]^{\mathrm{a}}$} & & 303 & 101 & {$[27]^{\mathrm{a}},[32]^{\mathrm{a}}$} \\
\hline & & 303 & 101 & {$[35]^{\mathrm{a}}$} & & 308 & 101 & {$[32]^{\mathrm{a}}$} \\
\hline & & 318 & 101 & {$[34]^{\mathrm{a}}$} & & 313 & 101 & {$[32]^{\mathrm{a}}$} \\
\hline & & 363 & 16200 & {$[36]^{a}$} & & & & \\
\hline & & 413 & 13760 & {$[36]^{a}$} & & & & \\
\hline \multirow[t]{7}{*}{$\mathrm{C}_{7} \mathrm{H}_{16}$} & VLE & - & 101 & This work & $v^{\mathrm{E}}$ & 291 & 101 & This work \\
\hline & VLE & - & 101 & {$[13]^{\mathrm{a}}$} & & 298 & 101 & This work \\
\hline & LLE & - & 0.7 & {$[16]$} & & 318 & 101 & This work \\
\hline & LLE & - & 82 & [17] & & 298 & 101 & {$[13]^{a},[24]^{a},[26]^{a},[29]^{a},[30]^{a},[33]^{a}$} \\
\hline & $h^{\mathrm{E}}$ & 291 & 101 & This work & $c_{\mathrm{p}}^{\mathrm{E}}$ & 298 & 101 & {$[29]$} \\
\hline & & 298 & 101 & {$[13]^{\mathrm{a}},[22],[34]^{\mathrm{a}},[37]^{\mathrm{a}}$} & & & & \\
\hline & & 318 & 101 & {$[23]$} & & & & \\
\hline \multirow[t]{5}{*}{$\mathrm{C}_{8} \mathrm{H}_{18}$} & VLE & - & 101 & This work & $v^{\mathrm{E}}$ & 291 & 101 & This work \\
\hline & LLE & - & 1.1 & [16] & & 298 & 101 & This work \\
\hline & $h^{\mathrm{E}}$ & 291 & 101 & This work & & 318 & 101 & This work \\
\hline & & 318 & 101 & This work & & 298 & 101 & {$[18]^{a},[26]^{a},[28]^{a},[31]^{a},[33]^{a}$} \\
\hline & & 298 & 101 & {$[18],[33]^{\mathrm{a}},[38]^{\mathrm{a}}$} & & & & \\
\hline \multirow[t]{5}{*}{$\mathrm{C}_{9} \mathrm{H}_{20}$} & VLE & - & 101 & This work & $v^{\mathrm{E}}$ & 291 & 101 & This work \\
\hline & LLE & - & 1.8 & [16] & & 298 & 101 & This work \\
\hline & $h^{\mathrm{E}}$ & 291 & 101 & This work & & 318 & 101 & This work \\
\hline & & 298 & 101 & {$[21],[38]^{\mathrm{a}}$} & & 298 & 101 & {$[24]^{\mathrm{a}},[30]^{\mathrm{a}}$} \\
\hline & & 318 & 101 & [23] & & 318 & 101 & {$[23]^{\mathrm{a}}$} \\
\hline \multirow[t]{4}{*}{$\mathrm{C}_{10} \mathrm{H}_{22}$} & VLE & - & 101 & This work & $v^{\mathrm{E}}$ & 291 & 101 & This work \\
\hline & $h^{\mathrm{E}}$ & 291 & 101 & This work & & 298 & 101 & This work \\
\hline & & 318 & 101 & This work & & 318 & 101 & This work \\
\hline & & 298 & 101 & [20] & & 298 & 101 & {$[20]^{a},[31]^{a},[33]^{a}$} \\
\hline
\end{tabular}

a Data not used in the correlation procedure of the corresponding system.

[12] produced acceptable estimates for isobaric VLE, although it did not show the change in $h^{\mathrm{E}}$ values with temperature.

Another part of this work, of a more theoretical nature, focuses on presenting a procedure for the simultaneous treatment of data on different thermodynamic properties for a given binary system with a flexible model already used and whose capacity to solve certain complex cases attempts to be evaluated. In previous works $[40,43]$, different situations were proposed that initially presented obstacles to application of the model but that were resolved oneby-one. The model has been shown to have a good flexibility and can be used to set and meet increasingly complex goals. Hence, the presence of LLE and VLE data (iso- $p$ and iso- $T$ ), and mixing properties, $h^{\mathrm{E}}, g^{\mathrm{E}}, v^{\mathrm{E}}$ and $c_{\mathrm{p}}^{\mathrm{E}}$, for the binary systems selected, gave rise to new problems that the authors propose to resolve.

\subsection{Modeling approach}

One of the most interesting approaches in thermodynamic studies on phase equilibria is to represent/correlate qualitative/quantitative behavior of phase equilibria, which can be used to estimate characteristics of the phases (pressure, temperature and composition) when experimental data are not available. Several attempts have been made in this area to develop thermodynamic models of the activity coefficients or $g^{\mathrm{E}}$, with Equations of State (EOS), or combinations of these, EOS $/ \mathrm{g}^{\mathrm{E}}$, although the application of these mixing rules often results in a distortion of the model and/or the EOS. The number of adjustable parameters of the multifunctional model created in this way increases and the representation obtained is probably limited. In other cases, $g^{\mathrm{E}}$ is considered to be independent of pressure, which is incorrect; these are general rules because they depend on the nature of compounds studied and on the working conditions and therefore the utilization of those presents some limitations. The reality is often complex, as sometimes proposed with the experimental data available.

Before we focus on the experimental data available in this work, we can describe some unexpected occurrences. On the one hand, the $h^{\mathrm{E}}=h^{\mathrm{E}}(x, T)$ curves present an inversion as $T$ advances, which mathematically corresponds to a minimum of the previous function, which makes the coefficient $c_{\mathrm{p}}^{\mathrm{E}}=\left(\partial h^{\mathrm{E}} / \partial T\right)_{\mathrm{p}}=0$ at that point. Hence, the succession of curves $h^{\mathrm{E}}=h^{\mathrm{E}}(T)$ graphically generates a hyperbolic paraboloid such as that of Fig. 1a. On the other hand, the presence of LLE data at low pressures for the methyl ethanoate + alkane systems signifies the presence of data in a plane, such as the isobaric $p_{5}$ in Fig. 1b, much lower than experimental values of VLE presented here (at $101.32 \mathrm{kPa}$ ), be for example the plane $p_{3}$, of the same figure. Hence, the treatment of data does not correspond to a case of VLLE but rather to the representation of curves in different planes of constant pressure (VLE and LLE) that correspond to the same surface, similar to the one represented in Fig. $1 \mathrm{~b}$ for a generic case. The observation made about the graphs clearly reflects the difficulty of finding a single model that represents the different properties of a binary fluid system considering all the points mentioned.

The NRTL model [44] is probably one of the most used in the field of thermodynamics of solutions, so some of its more extended forms should be used [45-47] to also analyze the goodness of fit 

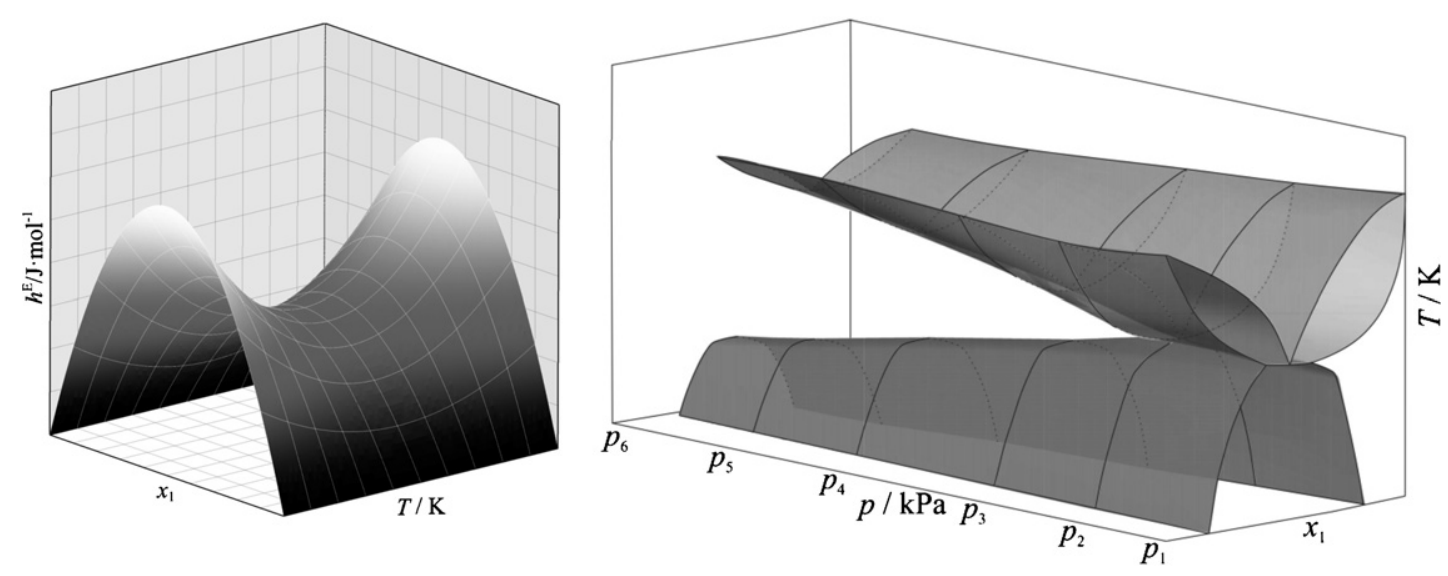

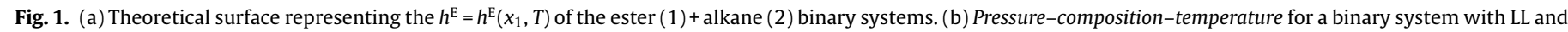
VL phase equilibria.

in these complex cases. Similarly, an important objective of this research is to provide a detailed explanation of the value of an extended form of the model previously used by the authors [40-43] which, implemented on excess Gibbs function for multicomponent systems $g^{\mathrm{E}}=g^{\mathrm{E}}\left(p, T, x_{1}\right)$, allows a multiproperty representation of solutions, using the same set of parameters for which we try to obtain optimum values. A correlative procedure must be designed for these theoretical models with a thorough analysis of the goodness of fit of the correlation/representation of surface areas such as those in Fig. 1a and b, since the minimization of errors offers more accurate subsequent simulations of separation processes where they are used.

\section{Experimental}

\subsection{Materials}

The chemical compounds used (methyl ethanoate and alkanes) are of the highest commercial purity $(\approx 0.99 \mathrm{w} / \mathrm{w})$ supplied by Aldrich. They were all degasified with ultrasound for several hours and treated with a $0.3 \mathrm{~nm}$ molecular sieve by Fluka to reduce the water contents. The quality of all the products was checked by GC (HP-9850 with FID) and the purity levels are reported in Table 2. Furthermore, some physical properties were measured for all them, such as the normal boiling point $T_{\mathrm{b}, i}^{\mathrm{o}}$, the density $\rho$, and the refractive index $n_{\mathrm{D}}$, at several temperatures. A comparison of the values obtained with those recorded in the literature (see Table 3) confirms the quality of the substances used in this work. The densities of nonane are particularly significant as they are used to calibrate the densimeter as described below. Water used to calibrate the apparatus was obtained by double distillation in our laboratory and degasified, giving a resulting electric conductance lower than $1 \mu \mathrm{S}$.

Table 2

Description of the material used.

\begin{tabular}{|c|c|c|c|}
\hline Compound & Manufacturer & $\begin{array}{l}\text { Mass fraction } \\
\text { purity }\end{array}$ & $\begin{array}{l}\text { Purification } \\
\text { method }\end{array}$ \\
\hline Methyl ethanoate & Aldrich & $>0.995$ & None \\
\hline Pentane & Aldrich & $>0.990$ & None \\
\hline Hexane & Aldrich & $>0.990$ & None \\
\hline Heptane & Aldrich & $>0.993$ & None \\
\hline Octane & Aldrich & $>0.987$ & None \\
\hline Nonane & Aldrich & $>0.990$ & None \\
\hline Decane & Aldrich & $>0.992$ & None \\
\hline
\end{tabular}

\subsection{Apparatus and procedures}

The density of all the pure compounds and mixtures of methyl ethanoate (1)+alkane (2) were measured at several temperatures using an Anton Paar DMA-55 digital densimeter, with a reading error of $\pm 0.02 \mathrm{~kg} \mathrm{~m}^{-3}$. The temperature of the oscillator was maintained stable at $T \pm 0.005 \mathrm{~K}$, and the water was circulated using a 9012 Polyscience thermostatic waterbath. The densimeter was calibrated with water and nonane at different working temperatures following the standard procedure used by our group. To determine $v^{\mathrm{E}}$ values at the different temperatures selected for this work, samples of known composition were prepared, with $x_{1} \pm 0.0002$, and the values obtained for volumes had an uncertainty of $\pm 2 \times 10^{-9} \mathrm{~m}^{3} \mathrm{~mol}^{-1}$. In this way, data of $\left(x, \rho, v^{\mathrm{E}}\right)$ were obtained which can be used to define the corresponding representations. Refractive indices $n_{D}$ for each compound were measured with a Zuzi 320 Abbe type refractometer with a reading error of \pm 0.0002 units. The refractometer was thermostatized at each of the temperatures with the previously described circulating water bath.

The mixing enthalpies $h^{\mathrm{E}}$ were measured for the binaries $\mathrm{CH}_{3} \mathrm{COOCH}_{3}+\mathrm{C}_{n} \mathrm{H}_{2 n+2}$ at different temperatures in a MS80D Calvet conduction calorimeter by Setaram, Lyon (France). The apparatus was electrically calibrated at each temperature for Joule effect using an EJ3 Setaram power source. Thermograms were recorded using the Setsoft $\odot$ commercial software from the same company. Real temperatures of the cells were adjusted as indicated in a previous work [40], to achieve the preset values. The apparatus was tested at the temperatures $298.15 \mathrm{~K}$ and $318.15 \mathrm{~K}$ with the propanol + benzene mixture [51]. A comparison of the curves in the literature for these cases resulted in a mean value for uncertainty lower than $1 \%$ for $h^{\mathrm{E}}$ and of \pm 0.0003 for the mole fraction.

The quantities that define isobaric $\operatorname{VLE}(p, T, x, y)$ for the selected systems were measured in a glass ebullometer of $60 \mathrm{~cm}^{3}$ used with recirculation of both phases, described previously [52], with additional elements described in another work [40]. Determinations of the compositions at equilibrium were obtained using a densimeter after reaching stable values for pressure, at $(101.32 \pm 0.02) \mathrm{kPa}$ and temperature at $(T \pm 0.02) \mathrm{K}$, which was achieved after an average time of $15-20 \mathrm{~min}$. A sample was taken from each of the phases and sent to densimeter at $T=298.15 \mathrm{~K}$. Liquid $x_{1}$ and vapor $y_{1}$ compositions were estimated by a recursive procedure with the equation: $\rho\left(x_{1}\right)=\left[\left(\rho_{1}-\rho_{2}\right) x_{1}+\rho_{2}\right]+\left[x_{1}\left(1-x_{1}\right)\left(a x_{1}^{2}+b x_{1}+c\right)\right]$, where $\rho, \rho_{1}$, and $\rho_{2}$ are the densities, respectively, of the samples, of the methyl ester and the alkane; the coefficients $a, b$ and $c$ of the previous expression are obtained beforehand in the correlation 
Table 3

Properties $^{\mathrm{a}}$ of Pure Compounds. Densities and refractive indices were measured at atmospheric pressure.

\begin{tabular}{|c|c|c|c|c|c|c|c|}
\hline \multirow[t]{2}{*}{ Component } & \multicolumn{2}{|l|}{$T_{\mathrm{b}, i}^{\mathrm{o}}(\mathrm{K})$} & \multirow[t]{2}{*}{$T(\mathrm{~K})$} & \multicolumn{2}{|c|}{$\rho\left(\mathrm{kg} \mathrm{m}^{-3}\right)$} & \multicolumn{2}{|l|}{$n_{D}$} \\
\hline & Exp & Lit & & Exp & Lit & Exp & Lit \\
\hline $\mathrm{CH}_{3} \mathrm{CHOOCH}_{3}$ & 330.08 & $\begin{array}{l}329.47^{b} \\
329.85^{c}\end{array}$ & $\begin{array}{l}291.15 \rightarrow \\
298.15 \rightarrow \\
318.15 \rightarrow\end{array}$ & $\begin{array}{l}935.92 \\
927.01 \\
900.07\end{array}$ & $\begin{array}{l}934.89^{\mathrm{e}} \\
927.90^{\mathrm{b}} \\
927.14^{\mathrm{c}} \\
900.20^{\mathrm{d}} \\
900.1^{\mathrm{g}}\end{array}$ & $\begin{array}{l}1.3632 \\
1.3589\end{array}$ & $\begin{array}{l}1.3589^{\mathrm{b}, \mathrm{c}, \mathrm{d}} \\
1.3485^{\mathrm{d}}\end{array}$ \\
\hline $\mathrm{CH}_{3}\left(\mathrm{CH}_{2}\right)_{3} \mathrm{CH}_{3}$ & 309.30 & $309.22^{\mathrm{b}}$ & $\begin{array}{l}291.15 \rightarrow \\
298.15 \rightarrow\end{array}$ & $\begin{array}{l}628.22 \\
621.35\end{array}$ & $\begin{array}{l}628.28^{e} \\
621.39^{b}\end{array}$ & $\begin{array}{l}1.3589 \\
1.3545\end{array}$ & $1.3547^{\mathrm{b}}$ \\
\hline $\mathrm{CH}_{3}\left(\mathrm{CH}_{2}\right)_{4} \mathrm{CH}_{3}$ & 341.88 & $\begin{array}{l}341.89^{b} \\
341.93^{f}\end{array}$ & $\begin{array}{l}291.15 \rightarrow \\
298.15 \rightarrow \\
318.15 \rightarrow\end{array}$ & $\begin{array}{l}661.17 \\
654.84 \\
636.50\end{array}$ & $\begin{array}{l}661.49^{d} \\
654.84^{b} \\
654.59^{f} \\
636.39^{f} \\
636.67^{d}\end{array}$ & $\begin{array}{l}1.3767 \\
1.3723 \\
1.3615\end{array}$ & $\begin{array}{l}1.37226^{\mathrm{b}} \\
1.3615^{\mathrm{d}}\end{array}$ \\
\hline $\mathrm{CH}_{3}\left(\mathrm{CH}_{2}\right)_{5} \mathrm{CH}_{3}$ & 371.56 & $\begin{array}{l}371.58^{b} \\
371.18^{f}\end{array}$ & $\begin{array}{l}291.15 \rightarrow \\
298.15 \rightarrow \\
318.15 \rightarrow\end{array}$ & $\begin{array}{l}685.28 \\
679.48 \\
662.06\end{array}$ & $\begin{array}{l}685.56^{\mathrm{e}} \\
679.46^{\mathrm{b}} \\
679.27^{\mathrm{f}} \\
661.47^{\mathrm{f}} \\
662.32^{\mathrm{d}}\end{array}$ & $\begin{array}{l}1.3886 \\
1.3852 \\
1.3748\end{array}$ & $\begin{array}{l}1.38511^{\mathrm{b}} \\
1.3750^{\mathrm{d}}\end{array}$ \\
\hline $\mathrm{CH}_{3}\left(\mathrm{CH}_{2}\right)_{6} \mathrm{CH}_{3}$ & 398.83 & $\begin{array}{l}398.82^{b} \\
398.65^{f}\end{array}$ & $\begin{array}{l}291.15 \rightarrow \\
298.15 \rightarrow \\
318.15 \rightarrow\end{array}$ & $\begin{array}{l}704.13 \\
698.60 \\
682.16\end{array}$ & $\begin{array}{l}704.33^{\mathrm{e}} \\
698.62^{\mathrm{b}} \\
698.39^{\mathrm{f}} \\
682.09^{\mathrm{f}} \\
682.09^{\mathrm{d}}\end{array}$ & $\begin{array}{l}1.3994 \\
1.3952 \\
1.3855\end{array}$ & $\begin{array}{l}1.39505^{\mathrm{b}} \\
1.3855^{\mathrm{d}}\end{array}$ \\
\hline $\mathrm{CH}_{3}\left(\mathrm{CH}_{2}\right)_{7} \mathrm{CH}_{3}$ & 423.94 & $\begin{array}{l}423.95^{b} \\
423.97^{f}\end{array}$ & $\begin{array}{l}291.15 \rightarrow \\
298.15 \rightarrow \\
318.15 \rightarrow\end{array}$ & $\begin{array}{l}719.25 \\
713.85 \\
698.07\end{array}$ & $\begin{array}{l}719.44^{\mathrm{e}} \\
713.42^{\mathrm{b}} \\
713.85^{\mathrm{f}} \\
698.06^{\mathrm{f}} \\
698.06^{\mathrm{d}}\end{array}$ & $\begin{array}{l}1.4062 \\
1.4031\end{array}$ & $\begin{array}{l}1.40311^{\mathrm{b}} \\
1.3939^{\mathrm{d}}\end{array}$ \\
\hline $\mathrm{CH}_{3}\left(\mathrm{CH}_{2}\right)_{8} \mathrm{CH}_{3}$ & 447.30 & $\begin{array}{l}447.27^{b} \\
447.30^{f}\end{array}$ & $\begin{array}{l}291.15 \rightarrow \\
298.15 \rightarrow \\
318.15 \rightarrow\end{array}$ & $\begin{array}{l}731.23 \\
726.20 \\
710.90\end{array}$ & $\begin{array}{l}731.39^{\mathrm{e}} \\
726.35^{\mathrm{b}} \\
726.19^{\mathrm{f}} \\
711.14^{\mathrm{f}} \\
711.43^{\mathrm{d}}\end{array}$ & $\begin{array}{l}1.4115 \\
1.4096\end{array}$ & $\begin{array}{l}1.40967^{\mathrm{b}} \\
1.4008^{\mathrm{d}}\end{array}$ \\
\hline
\end{tabular}

a Uncertainties $u$ are: $u(T)= \pm 0.02 \mathrm{~K}, u(n)= \pm 0.0002$, and $u(\rho)= \pm 0.02 \mathrm{~kg} \mathrm{~m}^{-3}$.

b Ref. [48].

c Ref. [13].

d Ref. [49].

e Ref. [50].

f Ref. [40].

g Ref. [23].

of experimental data of synthetically prepared samples. The same ebullometer was used to measure the vapor pressures of methyl ethanoate in the range $T=300-350 \mathrm{~K}$.

\section{Results and discussion}

\subsection{Presentation and treatment of excess properties}

Excess volumes and enthalpies were determined for the binary mixtures, whose empirical formulation is: $\mathrm{CH}_{3} \mathrm{COOCH}_{3}$ (1) $+\mathrm{C}_{n} \mathrm{H}_{2 n+2}(2)(n=5-10)$, at the temperatures of $291.15,298.15$ and $318.15 \mathrm{~K}$, except for the mixture with $n=5$ for which the mixing properties were not measured at $318.15 \mathrm{~K}$, a temperature higher than their normal boiling point. The series of data $\left(x_{1}, \rho, v^{\mathrm{E}}\right)$ are shown in Table S1 in Supporting information (SI) while Table S2 (SI) shows the pairs of values $\left(x_{1}, h^{\mathrm{E}}\right)$ at $291.15 \mathrm{~K}$ for all the mixtures and at the temperature $318.15 \mathrm{~K}$ only for those corresponding to even hydrocarbons. The values of $h^{\mathrm{E}}$ at the temperature of $298.15 \mathrm{~K}$ for these mixtures have been presented in previous works [13,18-25].

Both excess properties were correlated with a previously used polynomial equation:

$y^{\mathrm{E}}=z_{1}\left(1-z_{1}\right) \sum_{i=0}^{2} a_{i} z_{1}^{i}=z_{1}\left(1-z_{1}\right)\left(a_{0}+a_{1} z_{1}+a_{2} z_{1}^{2}\right)$ where the correlation coefficients are functions of temperature according to the expression,

$a_{i}(T)=\sum_{j=1}^{3} A_{i j} T^{j-2}=\frac{A_{i 1}}{T}+A_{i 2}+A_{i 3} T$

The active fraction of the ester $z_{1}$ depends on its molar fraction $x_{1}$ and on a characteristic parameter of each mixture $k$,

$z_{1}=\frac{x_{1}}{x_{1}+k x_{2}}$

The parameter $k$ is related to a physical magnitude that depends on $v^{\mathrm{E}}, h^{\mathrm{E}}$, or another property. For correlation of the property volume, this parameter is called $k_{\mathrm{v}}$ and is calculated from the quotient of the molar volumes of both pure components, and its value coincides with that of the volumetric fraction. In the correlation of enthalpic data, the parameter is called $k_{\mathrm{h}}$, and it is calculated from the ratio of the molar surfaces of the components by the expression,

$k_{\mathrm{h}}=\left(\frac{q_{2}}{q_{1}}\right)\left(k_{\mathrm{v}} \frac{r_{2}}{r_{1}}\right)^{2 / 3}$

where $q_{i}$ and $r_{i}(i=1,2)$ are the parameters for area and volume calculated by applying a group contribution method proposed by Bondi [53]. The coefficients $A_{i j}$ of Eq. (2) are obtained by a 
Table 4

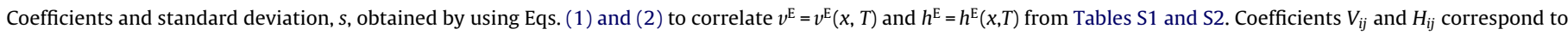
the $A_{i j}$ defined for Eq. (2)

\begin{tabular}{|c|c|c|c|c|c|c|}
\hline Methyl ethanoate (1)+ & Pentane & Hexane & Heptane & Octane & Nonane & Decane \\
\hline$V_{01}$ & $1.059 \mathrm{E} 7$ & 7.972E7 & $1.196 \mathrm{E} 8$ & 5.507E5 & 3.123E7 & 5.409E7 \\
\hline$V_{02}$ & $-3.635 \mathrm{E} 4$ & $-5.324 \mathrm{E} 5$ & $-7.930 \mathrm{E} 5$ & $-1.309 \mathrm{E} 4$ & $-2.102 \mathrm{E} 5$ & $-3.681 \mathrm{E} 5$ \\
\hline$V_{03}$ & 3.657E1 & $9.241 \mathrm{E} 2$ & $1.351 \mathrm{E} 3$ & 7.849E1 & $3.981 \mathrm{E} 2$ & $6.725 \mathrm{E} 2$ \\
\hline$V_{11}$ & $-5.247 \mathrm{E} 6$ & $-1.669 \mathrm{E} 8$ & $-3.663 \mathrm{E} 8$ & 2.903E7 & $-9.102 \mathrm{E} 7$ & $-2.296 \mathrm{E} 8$ \\
\hline$V_{12}$ & $-1.088 \mathrm{E} 5$ & 1.096E6 & 2.410E6 & $-1.790 \mathrm{E} 5$ & 5.840E5 & $1.523 \mathrm{E} 6$ \\
\hline$V_{13}$ & 3.590E2 & $-1.854 \mathrm{E} 3$ & $-4.016 \mathrm{E} 3$ & 2.107E2 & $-1.008 \mathrm{E} 3$ & $-2.602 \mathrm{E} 3$ \\
\hline$V_{21}$ & $-6.802 \mathrm{E} 6$ & 6.840E7 & 2.963E8 & 1.709E7 & $2.750 \mathrm{E} 7$ & 2.157E8 \\
\hline$V_{22}$ & $1.931 \mathrm{E} 5$ & $-4.449 \mathrm{E} 5$ & $-1.950 \mathrm{E} 6$ & $-1.220 \mathrm{E} 5$ & $-1.607 \mathrm{E} 5$ & $-1.423 \mathrm{E} 6$ \\
\hline$V_{23}$ & $-5.304 \mathrm{E} 2$ & $7.551 \mathrm{E} 2$ & 3.237E3 & 2.537E2 & 2.767E2 & 2.397E3 \\
\hline$k_{\mathrm{v}}$ & 1.452 & 1.646 & 1.844 & 2.044 & 2.245 & 2.448 \\
\hline $10^{9} s\left(v^{\mathrm{E}}\right)(T=291.1 \mathrm{~K})$ & 44 & 17 & 19 & 30 & 39 & 44 \\
\hline $10^{9} S\left(v^{\mathrm{E}}\right)(T=298.1 \mathrm{~K})$ & 41 & 13 & 20 & 16 & 33 & 45 \\
\hline $10^{9} S\left(v^{\mathrm{E}}\right)(T=318.1 \mathrm{~K})$ & - & 54 & 23 & 19 & 28 & 44 \\
\hline$H_{01}$ & $-7.379 \mathrm{E} 7$ & $-6.959 \mathrm{E} 7$ & $3.981 \mathrm{E} 8$ & $1.048 \mathrm{E} 8$ & 3.372E8 & $3.542 \mathrm{E}+08$ \\
\hline$H_{02}$ & 4.635E5 & 4.724E5 & $-2.607 \mathrm{E} 6$ & $-6.630 \mathrm{E} 5$ & $-2.186 \mathrm{E} 6$ & $-2.287 \mathrm{E}+06$ \\
\hline$H_{03}$ & $-6.955 \mathrm{E} 2$ & $-7.669 \mathrm{E} 2$ & 4.303E3 & $1.089 \mathrm{E} 3$ & $3.586 \mathrm{E} 3$ & $3.737 \mathrm{E}+03$ \\
\hline$H_{11}$ & 9.923E8 & $9.891 \mathrm{E} 8$ & $-7.937 \mathrm{E} 8$ & $1.955 \mathrm{E} 8$ & $-8.761 E+08$ & $-9.123 \mathrm{E}+08$ \\
\hline$H_{12}$ & $-6.488 \mathrm{E} 6$ & $-6.511 \mathrm{E} 6$ & 5.230E6 & $-1.338 \mathrm{E} 6$ & $5.693 \mathrm{E}+06$ & $5.880 \mathrm{E}+06$ \\
\hline$H_{13}$ & $1.058 \mathrm{E} 4$ & $1.068 \mathrm{E} 4$ & $-8.651 \mathrm{E} 3$ & $2.231 \mathrm{E} 3$ & $-9.298 \mathrm{E}+03$ & $-9.538 \mathrm{E}+03$ \\
\hline$H_{21}$ & $-7.768 \mathrm{E} 8$ & $-7.827 \mathrm{E} 8$ & $7.762 \mathrm{E} 8$ & $-1.267 \mathrm{E} 8$ & $9.782 \mathrm{E}+08$ & $1.007 \mathrm{E}+09$ \\
\hline $\mathrm{H}_{22}$ & $5.131 \mathrm{E} 6$ & 5.150E6 & $-5.114 \mathrm{E} 6$ & 8.789E5 & $-6.379 E+06$ & $-6.519 E+06$ \\
\hline$H_{23}$ & $-8.465 \mathrm{E} 3$ & $-8.447 \mathrm{E} 3$ & 8.438E3 & $-1.488 \mathrm{E} 3$ & $1.042 \mathrm{E}+04$ & $1.058 \mathrm{E}+04$ \\
\hline$k_{\mathrm{h}}$ & 1.342 & 1.523 & 1.706 & 1.869 & 2.076 & 2.263 \\
\hline$s\left(h^{\mathrm{E}}\right)(T=291.1 \mathrm{~K})$ & 17 & 16 & 7 & 13 & 15 & 33 \\
\hline$s\left(h^{\mathrm{E}}\right)(T=298.1 \mathrm{~K})$ & 16 & 9 & 11 & 15 & 5 & 15 \\
\hline$s\left(h^{\mathrm{E}}\right)(T=318.1 \mathrm{~K})$ & - & 7 & 18 & 14 & 13 & 21 \\
\hline
\end{tabular}

non-linear optimization procedure using as an objective function the equation;

$\mathrm{OF}=s\left(y^{\mathrm{E}}\right)=\left[\frac{\sum_{i=1}^{N_{\mathrm{p}}}\left(y_{i, \exp }^{\mathrm{E}}-y_{i, \mathrm{cal}}^{\mathrm{E}, \mathrm{cal}}\right)^{2}}{N_{\mathrm{p}}}\right]^{1 / 2}$

The same mathematical treatment was carried out for the $h^{\mathrm{E}}$ reported here and also for previously published values, which, as mentioned before were measured at another temperature.

Values of the coefficients $A_{i j}$ for each of the systems in the correlation of $v^{\mathrm{E}}$ and $h^{\mathrm{E}}$ are presented in Table 4 together with the standard deviations, $s\left(y^{\mathrm{E}}\right)$, of the fits. The correlation curves for these properties for each system are represented together with the experimental values in Fig. 2a-c for the volumes and in Fig. 3a-c for the enthalpies; the equimolar values are shown in the corresponding insets $\left(y^{\mathrm{E}}\right.$ a $\left.x_{1}=0.5\right)$, which are compared with values recorded in the literature as a function of the number of carbon atoms $n$ of the hydrocarbon. An overall view of the graphs and quantification of the goodness of fit, $s\left(y^{\mathrm{E}}\right)$, shows that the simultaneous correlation of the properties at different temperatures to achieve a single function $y^{\mathrm{E}}=y^{\mathrm{E}}(x, T)$ results in a slight reduction in the model's representational capacity (especially in the $v^{\mathrm{E}} v s x_{1}$ correlation), although for the group as a whole it may be considered as acceptable.

For the $v^{\mathrm{E}}$, all cases show that: $v^{\mathrm{E}}>0$ and $\left(\partial v^{\mathrm{E}} / \partial T\right)>0$, and the thermal coefficient for mixtures of methyl ethanoate (1)+alkanes (2) is quasi-linear. No data were found in the literature at $T=291.15 \mathrm{~K}$, although at $298.15 \mathrm{~K}$ the inset figure in $2 \mathrm{~b}$ compares our values with those recorded in the literature for the same mixtures. The experimental values are almost identical to ones we recorded and published previously $[13,18-24]$ and are similar to those recorded by Awwad et al. [28], however they were significantly different to those of other authors [14,26,29-33]. At the temperature of $318.15 \mathrm{~K}$ (see Fig. 2c) there is good agreement for methyl ethanoate $+\left(C_{7}, C_{9}\right)$ mixtures in comparison with previous experimental values [23]. Table S2 (SI) shows the experimental data of $\left(x_{1}, h^{\mathrm{E}}\right)$ for the systems in the experiment at $291.15 \mathrm{~K}$ for the complete set of mixtures and at $318.15 \mathrm{~K}$ only for binary mixtures for which " $n$ " is even, as the others have been reported previously [18-25]. The resulting parameters for the combined correlations of $h^{\mathrm{E}}=h^{\mathrm{E}}\left(x_{1}, T\right)$ are shown in Table 4; the corresponding graphs are shown in Fig. $3 \mathrm{a}-\mathrm{c}$, verifying that $h^{\mathrm{E}}>0$ in all cases. In the corresponding insets, it is observed a quasi-irregular increase in $h^{\mathrm{E}}$ at $x_{1}=0.5$, with hydrocarbon chain length, although there are no data in the literature for the comparison at $291.15 \mathrm{~K}$. The comparisons made with values found at $318.15 \mathrm{~K}$ [34] and at $298.15 \mathrm{~K}$ $[33,34,37]$ are acceptable, although there are differences in the measurements at $298.15 \mathrm{~K}$ obtained with pentane [14], octane and nonane [38]. From these graphs, deductions can be made about the behavior of the systems studied. The $h^{\mathrm{E}}$ and $v^{\mathrm{E}}$ tend to increase with increasing number of $-\mathrm{CH}_{2}$-groups in the saturated hydrocarbon, confirming the structural model previously established $[12,13]$ to describe the behavior of the systems. By contrast, a comparison of the mixtures containing other ethanoates shows that for the same alkane, the values of the mixing properties decrease with increased alkanolic chain length of the ethanoate due to a weakening of the dipole-dipole interaction, which is one of the causes of the effects commented.

It is important to emphasize the effect of temperature on the $h^{\mathrm{E}}$ values. In the mixtures studied, the slope $\left(\partial h^{\mathrm{E}} / \partial T\right)_{\mathrm{p}}$ changes direction owing to the fact that the variations in $h^{\mathrm{E}}\left(x_{1}, T\right)$ present a local minimum where, at least theoretically, $c_{\mathrm{p}}^{\mathrm{E}}\left(x_{1}, T\right)=0$ should be obeyed. The literature [29] presents $c_{\mathrm{p}}^{\mathrm{E}}\left(x_{1}, T\right)$ data for the mixture of methyl ethanoate (1) + heptane (2) at $T=298.15 \mathrm{~K}$, for which the fitting function becomes zero at two composition points $x_{1}=0.28$ and $x_{1}=0.89$, which could correspond to a maximum and minimum respectively, of the function $h^{\mathrm{E}}\left(x_{1}, T\right)$, that can generate a surface like the one shown in Fig. 1a. The mathematical treatment cannot be carried out with Eqs. (1) and (2), since a quadratic function is required in " $T$ ". Hence, by adding a term in $T^{2}$ to Eq. (2) and performing a simultaneous fit of $h^{\mathrm{E}}\left(x_{1}, T\right)$ and $c_{\mathrm{p}}^{\mathrm{E}}\left(x_{1}, T\right)$ with the resulting Eq. (1), a diagram like the one displayed in Fig. $3 d$ is obtained, in which the function gives rise to a minimum for the $h^{\mathrm{E}}(T)$ in $T=298 \mathrm{~K}$ and $x_{1}=0.525$; the maximum would correspond to $T=313 \mathrm{~K}$ and $x_{1}=0.516$. Although quantitatively the experimental values for $c_{\mathrm{p}}^{\mathrm{E}}\left(x_{1}, T\right)$ do not appear to have been reproduced, the 

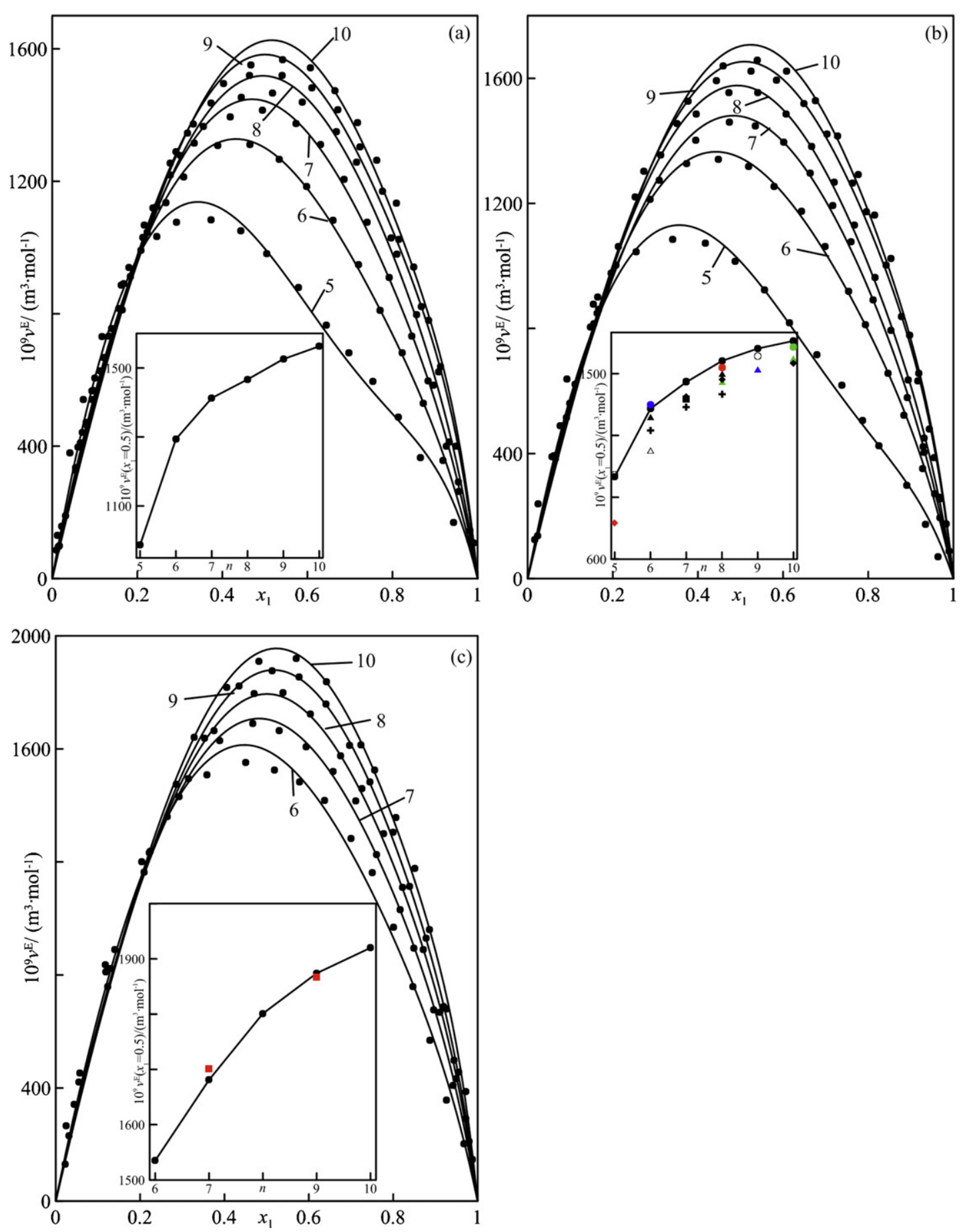

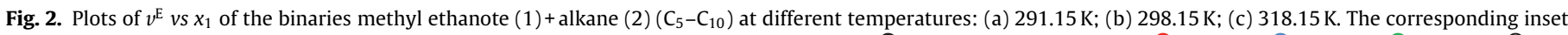

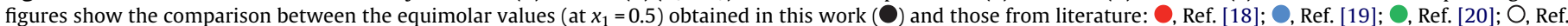
[24]; $\square$, Ref. [13]; $\square$, Ref. [23]; + , Ref. [26]; $\Delta$, Ref. [28]; $\Delta$, Ref. [29]; $\Delta$, Ref. [30]; $\Delta$, Ref. [31]; $\triangle$, Ref. [32]; $\diamond$, Ref. [33]; $\diamond$, Ref. [14].

function produces a significant gradient for the $c_{\mathrm{p}}^{\mathrm{E}}$, hence a slight variation in $T(\sim 0.15 \mathrm{~K})$ produces values for this property that are almost the same as the experimental value [29].

These "singular points" are referred to by some authors $[29,54]$ as the "omega effect" and are caused by a conformational change of the esters dissolved in the alkanes. The esters present a conformational equilibrium between the s-trans and s-cis forms, which signifies a change in its electrical dipole moment [54]. The dipolar moments of both conformations, calculated using the corresponding values for the $\mathrm{C}-\mathrm{O}$ and $\mathrm{C}=\mathrm{O}$ bonds, are 1.53 and 3.40 Debye for the $s$-trans and s-cis, conformations, respectively. The $s$-cis conformation ( $\mu=3-4$ Debye) stabilizes at high ester concentrations, while the $s$-trans conformation ( $\mu=1-2$ Debye) stabilizes at low ester concentrations, which causes the omega effect in the heat capacities, which are also a consequence of the thermal effects of the enthalpies. In other words, this unusual behavior of the esters in the mixtures occurs because its dipolar moments change with temperature. These observations could provoke an interesting debate about the presence of other singular points in the solutions, such as the azeotropic points, or the critical points (upper 

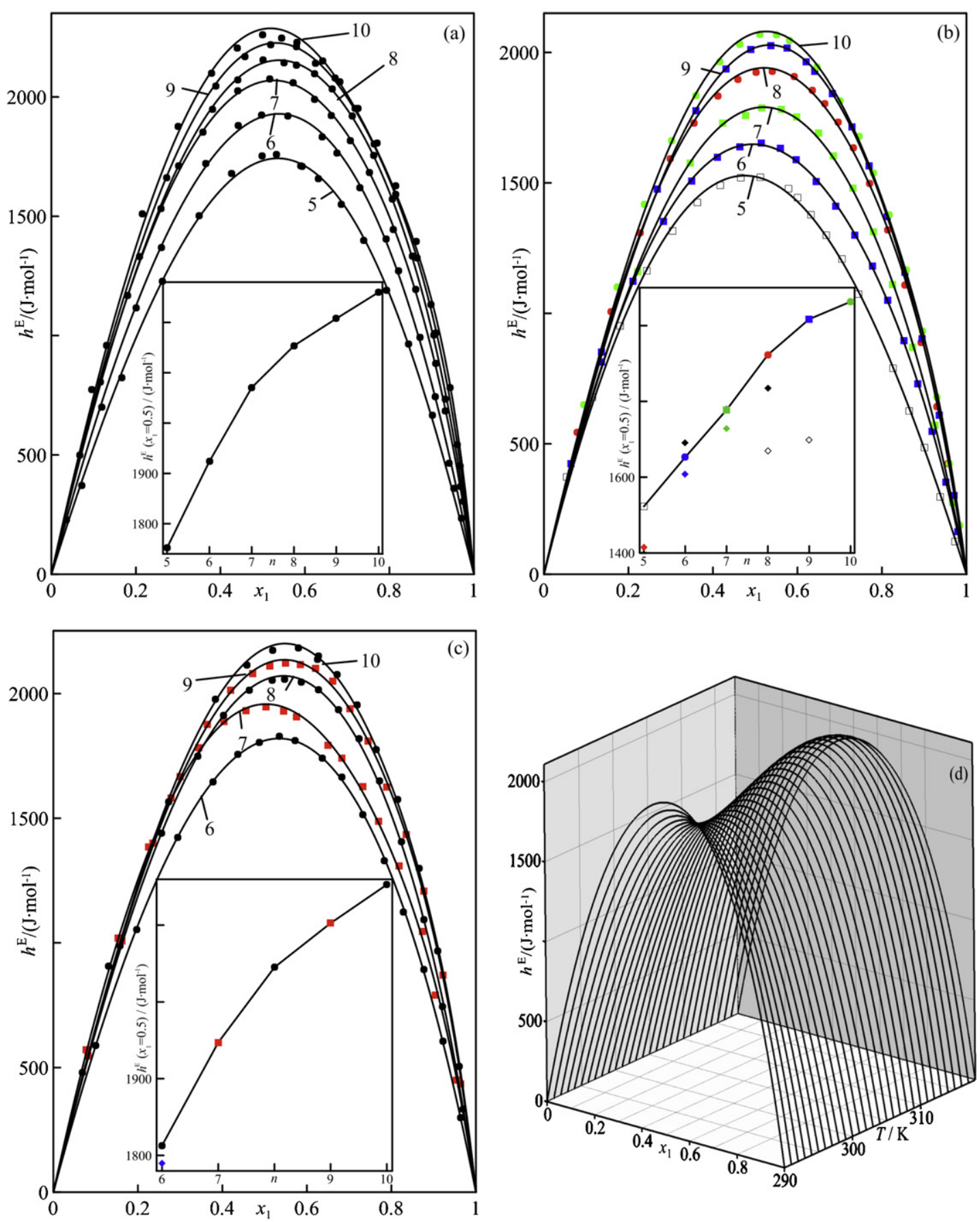

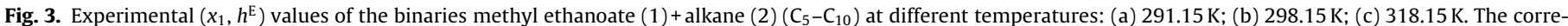

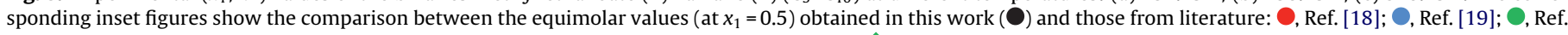

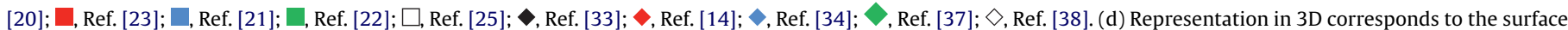
resulting of the simultaneous correlation of the pairs $\left[x_{1}, h^{\mathrm{E}}(T)\right]$ and $\left[x_{1}, c_{\mathrm{p}}^{\mathrm{E}}(298.15 \mathrm{~K})\right]$ using Eqs. (1) and (2) for the binary methyl ethanoate (1) + heptane (2).

and lower) of solubility, which are also caused by changes in conformational situations. We will study these points in future research.

\subsection{Vapor pressures}

Vapor pressures, or their correlations, influence the determination and verification of thermodynamic properties of VLE. Hence, for the series of works planned here for binary mixtures of ethanoates + alkanes, vapor pressures must be measured for all the compounds in a broader interval of temperatures and pressures.
The values and corresponding correlations for the alkanes have been recorded in a previous work [12], so here we have only included the values of methyl ethanoate. Table S3 gives the experimental $\left(T, p_{i}^{\circ}\right)$ data for the ester in the temperature range [300-350] K. Experimental values are correlated with a non-linear regression of Antoine's equation, obtaining the coefficients shown in Table 5, where the data are compared with others from the literature.

The coefficients $A, B$ and $C$ of this equation can be used to indirectly determine the values corresponding to the same equation in reduced coordinates, in order to obtain the acentric factor $\omega$ defined 
Table 5

Coefficients $A, B$, and $C$ of the Antoine equation: $\log \left(p_{i}^{\circ} / \mathrm{kPa}\right)=A-B[(T / \mathrm{K})-C]$ obtained fitting the values from Table S3, and acentric factor for methyl ethanoate.

\begin{tabular}{|c|c|c|c|c|}
\hline$A$ & $B$ & C & $\omega$ & $\Delta T / K$ \\
\hline 6.19788 & 1155.37 & 54.48 & & $300-350$ \\
\hline$(2.4858)^{\mathrm{a}}$ & $(2.2367)^{\mathrm{a}}$ & $(0.112)^{\mathrm{a}}$ & $0.321 ; 0.324^{\mathrm{d}} ; 0.320^{\mathrm{e}}$ & \\
\hline $6.1902^{\mathrm{b}}$ & $1157.62^{\mathrm{b}}$ & $53.43^{\mathrm{b}}$ & & \\
\hline $6.4934^{c}$ & $1329.46^{c}$ & $33.52^{c}$ & & \\
\hline
\end{tabular}

a Between parenthesis: coefficients $a, b, c$, obtained for the Antoine equation in reduced form: $\log \left(p_{i, \mathrm{x}}^{\mathrm{o}}\right)=a-b /\left[T_{\mathrm{r}}-c\right]$.

b Ref. [48].

c Ref. [7].

d Ref. [58].

e Ref. [56].

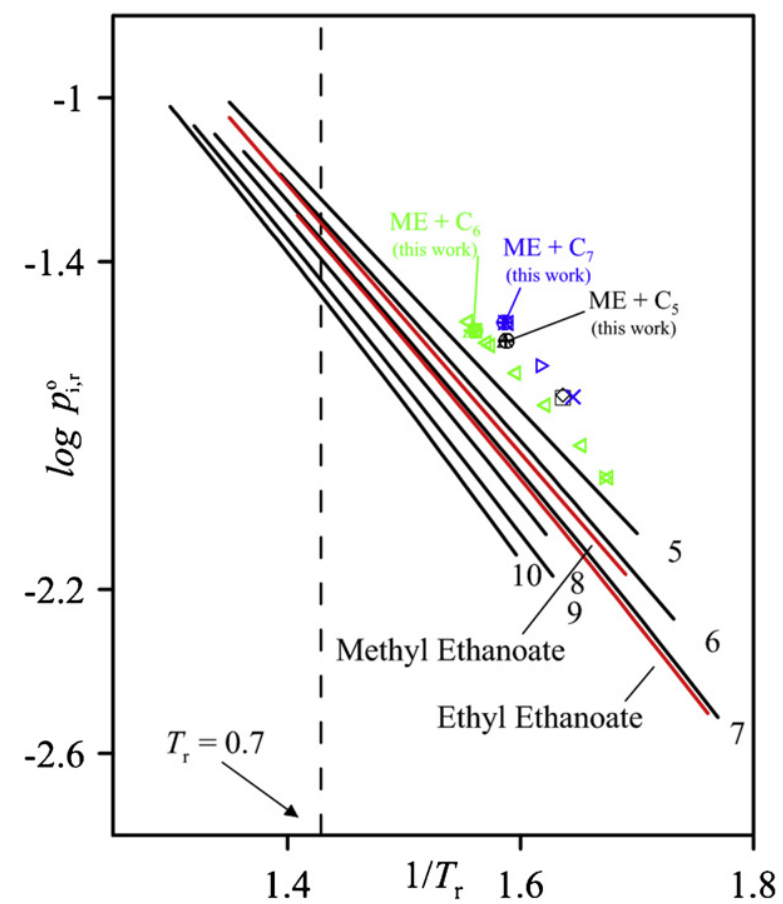

Fig. 4. Representation of the vapor pressures lines in reduced coordinates as a function of $\left(1 / T_{\mathrm{r}}\right)$ for methyl ethanoate (ME), ethyl ethanoate and alkanes $\left(C_{5}-C_{10}\right)$. Symbols represent the azeotropic points for $\mathrm{ME}+\mathrm{C}_{5}$ (black) and their comparison with those for $\mathrm{ME}+\mathrm{C}_{6}$ (green) and $\mathrm{ME}+\mathrm{C}_{7}$ (blue). + , this work; $\bigcirc$, Ref. [61]; $\square$, Ref. [15]; $\diamond$, Ref. [14]; $\nabla$, Ref. [62]; $\triangleright$, Ref. [63]; $\triangleleft$, Ref. [64]; X, Ref. [36]; *, Ref. [13]; $\triangle$, Ref. [39].

by Pitzer [55] as: $\omega=-\left(\log p_{i, \mathrm{r}}^{\mathrm{o}}\right)_{T_{\mathrm{r}}=0.7}-1$. However, better results are obtained by performing a direct correlation of the corresponding reduced quantities $\left(T_{\mathrm{r}}, p_{i, \mathrm{r}}^{\mathrm{o}}\right)$, which gives rise to values for $a, b$ and $c$, which are recorded in Table 5 (in parenthesis). In this way, the acentric factor can be obtained from: $\omega=b+(c-0.7)(a+1)$. The value obtained is found to be acceptable when compared with others in the literature or with that estimated by Lee-Kesler [56]. Fig. 4 shows the straight lines corresponding to $\log p_{i, \mathrm{r}}^{0}=\phi\left(1 / T_{\mathrm{r}}\right)$ for all the compounds of this work using the parameters obtained and the position sequence.

\subsection{Presentation of VLE data}

From the direct experimental values of VLE obtained in isobaric conditions of $p=(101.32 \pm 0.02) \mathrm{kPa},\left(p, T, x_{1}, y_{1}\right)$, for the six binary systems $\mathrm{CH}_{3} \mathrm{COOCH}_{3}(1)+\mathrm{C}_{n} \mathrm{H}_{2 n+2}(2)(n=5-10)$, it is necessary to calculate the values corresponding to the quantities that characterize the VLE. The activity coefficients are calculated by the expression:

$\ln \gamma_{i}=\ln \left(\frac{y_{i} p}{x_{i} p_{i}^{0}}\right)+\frac{\left(B_{i i}-v_{i}^{o}\right)\left(p-p_{i}^{o}\right)}{R T}+\frac{p \delta_{12}\left(1-y_{i}\right)^{2}}{R T}$

that considers the non-ideality of the vapor phase. Each of the quantities of Eq. (6) are obtained as follows: the vapor pressures $p_{i}^{o}$, by Antoine's equation, the molar volumes of the pure compounds $v_{i}^{o}$ at the equilibrium temperatures, with the modified version of Rackett's equation [57], using the parameters $Z_{\mathrm{RA}}$ published in Reid et al. [58], $\delta_{12}=2 B_{i j}-B_{i i}-B_{j j}$, from the virial coefficients which, for both the pure compounds $B_{i i}$ and $B_{j j}$ and also the mixtures $B_{i j}$, are estimated from the Tsonopoulos relationships [59]. With the $\left(x_{i}, \ln \gamma_{i}\right)$ values, those corresponding to adimensional excess Gibbs function, $g^{\mathrm{E}} / R T$, can be obtained for each equilibrium stage. All the $\gamma_{i}$ are compiled in Table S4 (SI) for the six systems studied and are shown in Figs. 5-10. The VLE data for this table satisfy the global condition proposed by Fredenslund [60] $\bar{\delta}=\sum\left|y_{i, \exp }-y_{i, \text { cal }}\right| / N \leq 0.01$ and are considered to be thermodynamically consistent. The $\gamma_{i}$ values of these mixtures emphasize the deviation from ideality of the liquid phase, and present a regular variation, with $\gamma_{2}$ increasing slightly with hydrocarbon chain length, while the $\gamma_{1}$ (for the methyl ethanoate) decreases, as do the relative areas of contact of the aliphatic portions, and therefore the degree of interaction between the molecules.

Other characteristic representations of the VLE using compositions and temperatures are reflected, respectively, in the form of $\left(y_{1}-x_{1}\right)$ vs $x_{1}$ and $T$ vs $x_{1}, y_{1}$. The comparison with literature data [13] for the binary with heptane is acceptable. The azeotropic points obtained, where $y_{1}-x_{1}=0$, corresponding to mixtures with methyl ethanoate $+\mathrm{C}_{n} \mathrm{H}_{2 n+2}(n=5,6,7)$ are recorded in Table S5 (SI), which compares data with those obtained by other authors [13-15,36,61-64]. Fig. 4 shows the corresponding points obtained using reduced variables and using as a mixing rule for the critical properties those determined by: $p_{\mathrm{c}, 12}=\sqrt{p_{\mathrm{c}, 1} \cdot p_{\mathrm{c}, 2}}$ and $T_{\mathrm{c}, 12}=\sqrt{T_{\mathrm{c}, 1} \cdot T_{\mathrm{c}, 2}}$. This proposal is a result of considering that the singular azeotropic point is the point of the vapor-liquid saturation curve corresponding to a pure compound, not taking into consideration its composition. From the graph it is evident that it is not easy to obtain a mathematical relationship for the different azeotropes for these mixtures using reduced quantities, although some aspects that have been studied previously will be addressed in future works.

\section{Procedure used for the multiproperty correlation}

\subsection{Proposed model}

The values obtained for the dimensionless excess Gibbs function, Table S4 (SI), can be used to create the data base for $g^{\mathrm{E}}(p, T$, $\left.x_{1}, y_{1}\right)$ for each of the systems. The correlation is made of the properties with a model and procedure previously used by the authors 

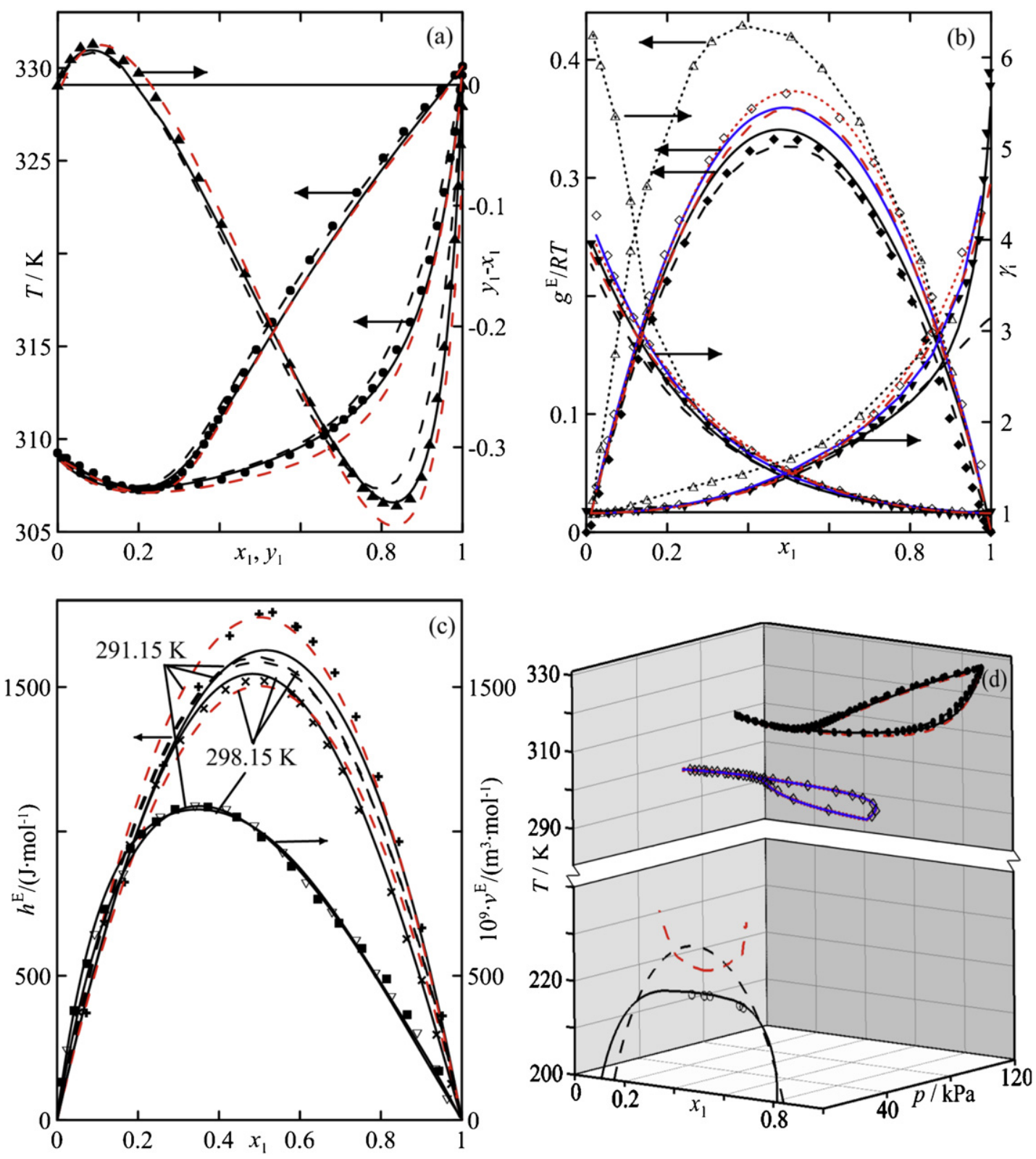

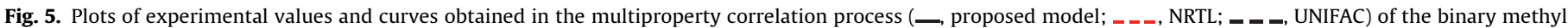

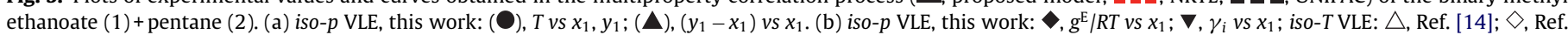

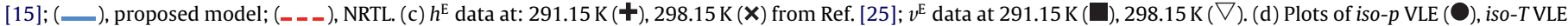
$(\diamond)$ and LLE (O) Ref. [16].

in other works [40-43]. The general form of the model, based on Gibbs function, and dependent on three variables, is as follows:

$g^{\mathrm{E}}(x, T, p)=[z(x)(1-z(x))]\left[g_{0}(T, p)+g_{1}(T, p) z(x)+g_{2}(T, p) z^{2}(x)\right]$

where the active fraction $z$, is defined by Eq. (3) and $g_{i}$ are coefficients $g_{i}=g_{i}(T, p)$ of fit. In the isobaric studies the coefficients are temperature-dependent alone according to a similar relationship to Eq. (2).

$g_{i}(T)=\sum_{j=1}^{3} G_{i j} T^{j-2}=\frac{G_{i 1}}{T}+G_{i 2}+G_{i 3} T$

The derivation of Eq. (7) can produce expressions for other thermodynamic properties. For example, the partial molar property of Gibbs function gives rise to the activity coefficients, which are calculated from the expression:

$R T \ln \gamma_{i}=\bar{g}_{i}^{\mathrm{E}}=g^{\mathrm{E}}-\sum_{k \neq i} x_{k}\left(\frac{\partial g^{\mathrm{E}}}{\partial x_{k}}\right)_{p, T, x_{j \neq k, i}}$

Using Eq. (7) the following expression is given for the activity coefficients,

$R T \ln \gamma_{i}=z(1-z) \sum_{j=0}^{2} g_{j} z^{j}+\left(1-x_{i}\right)\left[\sum_{j=0}^{3}(j+1)\left(g_{j}-g_{j-1}\right) z^{j}\right] k\left(\frac{z}{x_{i}}\right)^{2}$

This equation is true when $g_{-1}=g_{3}=0$. Another important quantity in studies on solutions is the excess enthalpy:

$h^{\mathrm{E}}=g^{\mathrm{E}}-T\left(\frac{\partial g^{\mathrm{E}}}{\partial T}\right)_{p, x}=z(1-z) \sum_{i=0}^{2} g_{i} z^{i}-T z(1-z) \sum_{i=0}^{2}\left(\frac{\partial g_{i}}{\partial T}\right) z^{i}-T Y\left(\frac{d z}{d T}\right)$ 

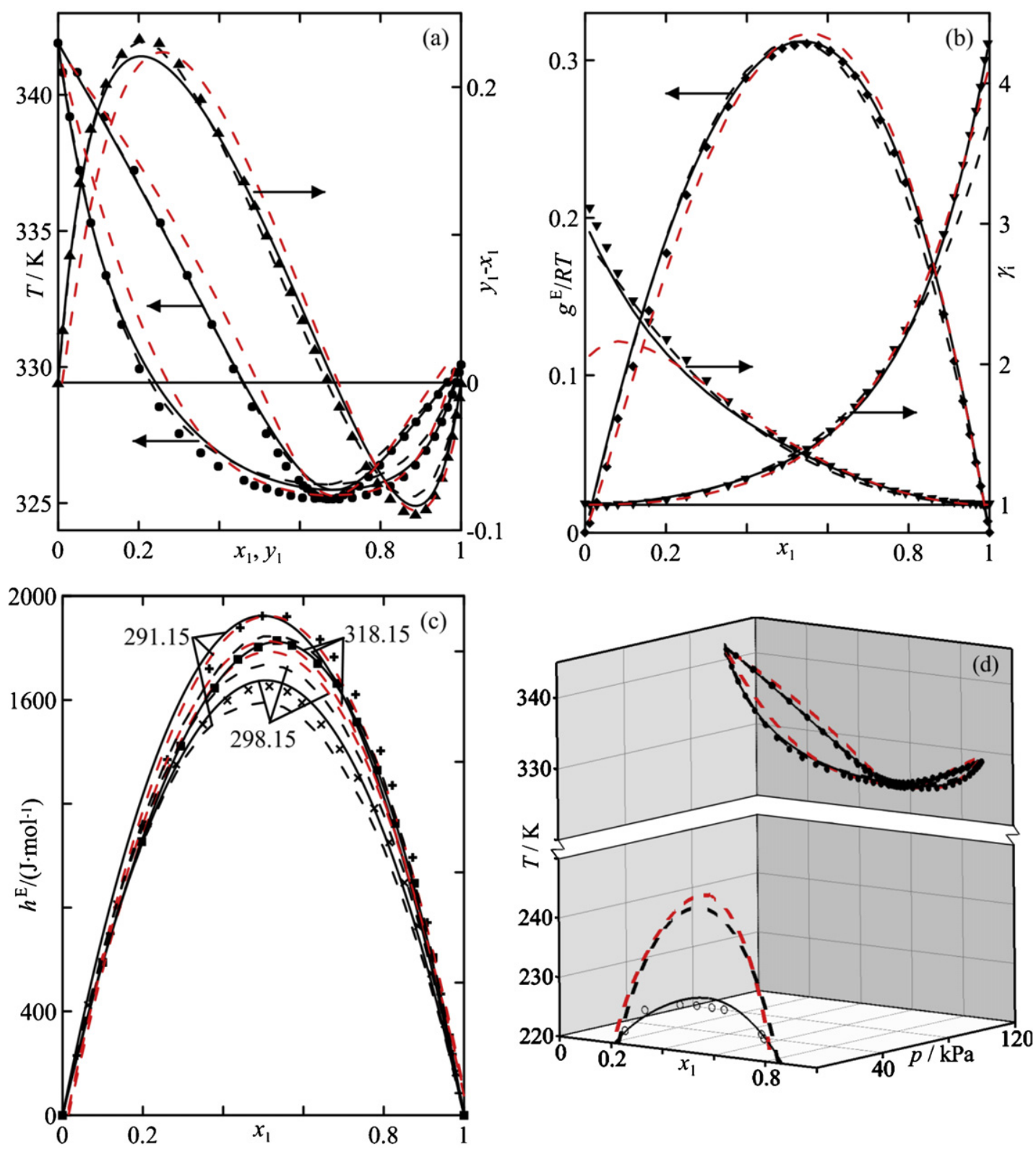

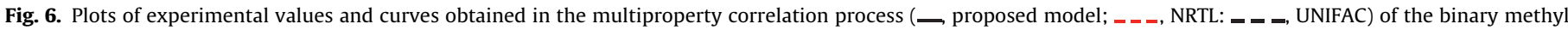

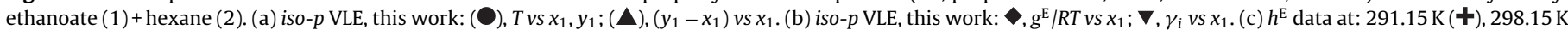
$(\mathbf{X})$, from Ref. [19], 318.15 K ( $\square$ ). (d) Plots of VLE (O) and LLE (O) Ref. [16].

where : $\quad Y=(1-2 z) \sum_{i=0}^{2} g_{i} z^{i}+z(1-z) \sum_{i=0}^{2} i g_{i} z^{i-1}$ and $z=z[x, k(T)]$

The third summand of Eq. (11) can be calculated using $(d z / d t)=(\partial z / \partial k)(d k / d t)$, however, as shown in previous works $[12,40]$, the variation in the parameter $k$ with temperature is minimum, nulling the corresponding term in Eq. (11) and the final expression is simplified as follow:

$h^{\mathrm{E}}=z(1-z) \sum_{i=0}^{2}\left(\frac{2 G_{i 1}}{T}+G_{i 2}\right) z^{i}$

From Eq. (13):

$c_{\mathrm{p}}^{\mathrm{E}}=\left(\frac{\partial h^{\mathrm{E}}}{\partial T}\right)_{\mathrm{p}, \mathrm{x}}=z(1-z) \sum_{i=0}^{2}\left[-T\left(\frac{\partial^{2} g_{i}}{\partial T^{2}}\right)_{\mathrm{p}, \mathrm{x}}\right] z^{i}=z(1-z) \sum_{i=0}^{2}\left(\frac{4 G_{i 1}}{T^{2}}\right) z^{i}$
When isothermal VLE data are available for the system being studied, the excess volumes can also be calculated by:

$v^{\mathrm{E}}=\left(\frac{\partial g^{\mathrm{E}}}{\partial p}\right)_{T, x}=z(1-z) \sum_{i=0}^{2}\left(\frac{\partial g_{i}}{\partial p}\right)_{T, x} z^{i}+\left(\frac{d z}{d p}\right) Y$

where $Y$ is Eq. (12). If the active fraction $z$ is considered to be independent of pressure, the entire summand is eliminated from Eq. (15). The advantage of the parametric model proposed is that it is useful to carry out correlations of multiproperties, depending on the demands or the level of accuracy required by the researcher. This is what gives the model its complexity, and sometimes other relationships are required for $g_{i}=g_{i}(T, p)$, other than 

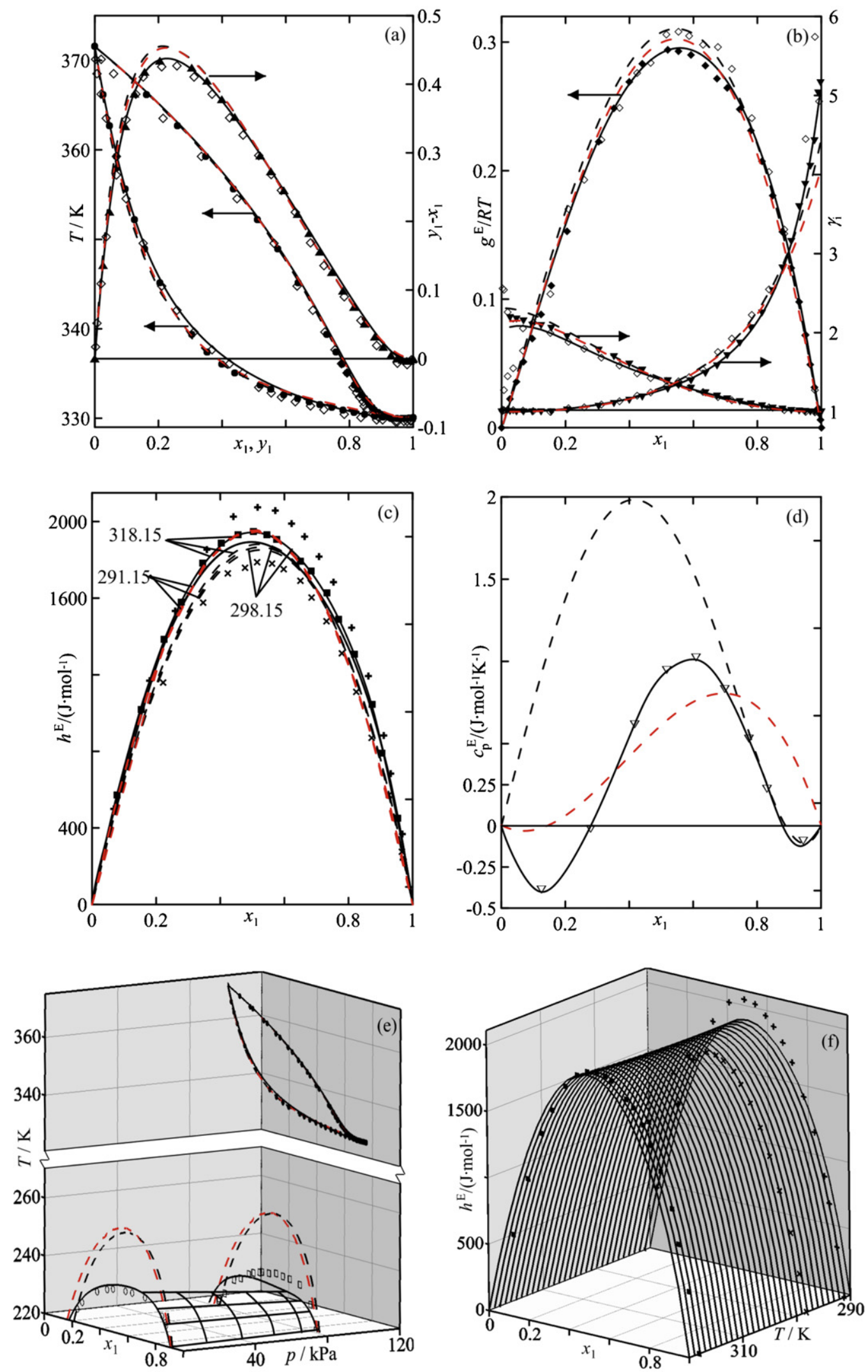

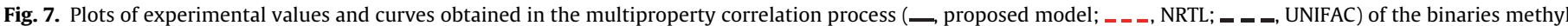

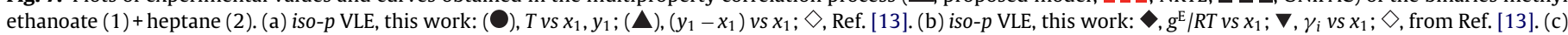

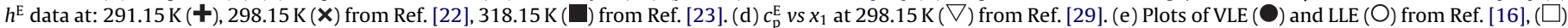
Ref. [17]. (f) Plots in 3D of the surface $h^{\mathrm{E}}\left(x_{1}, T\right)$ resulting of the multiproperty correlation for methyl ethanoate (1) + heptane (2) 

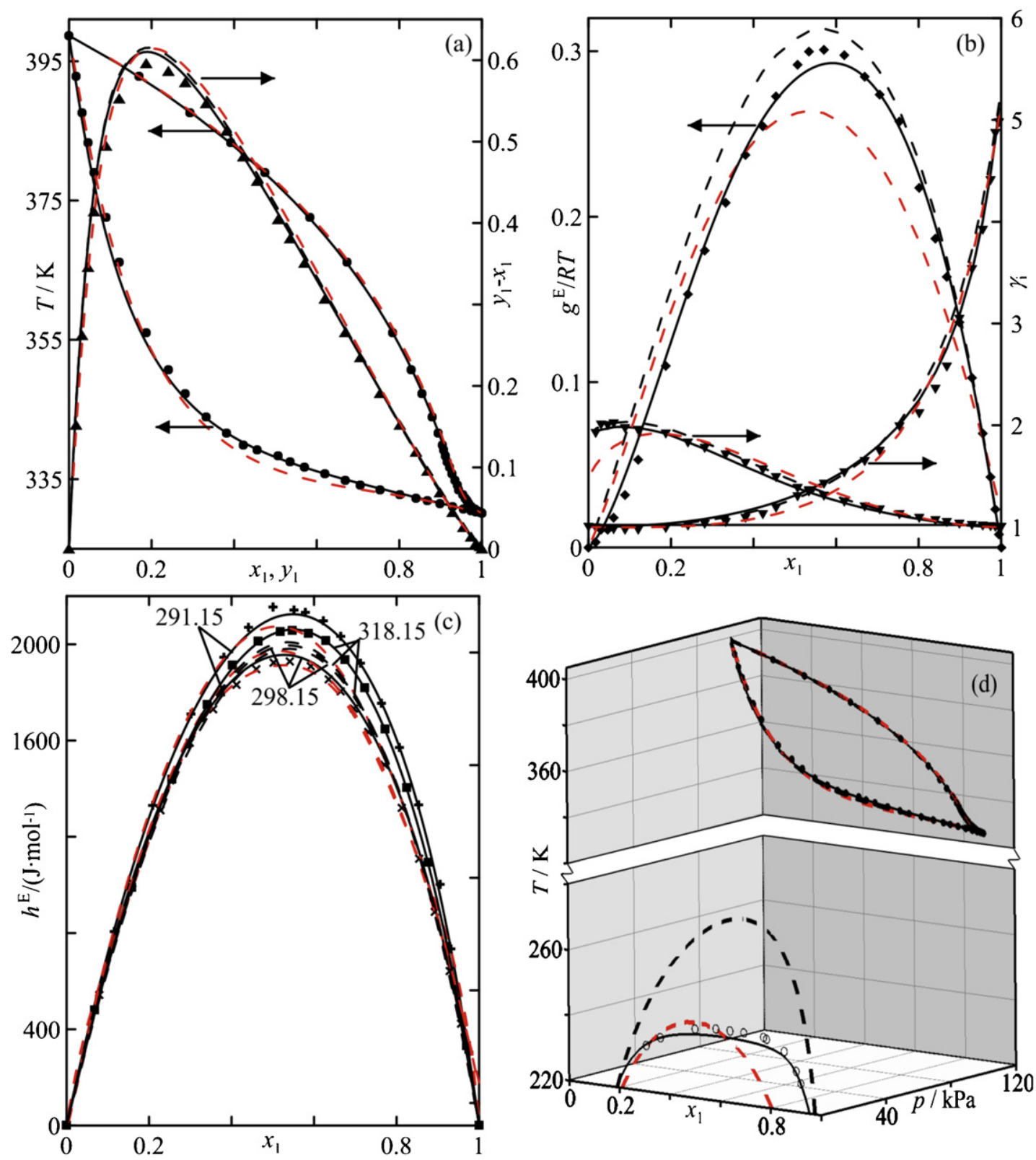

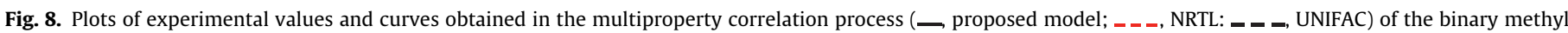

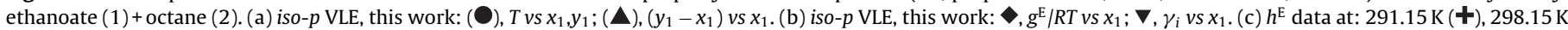
$(\mathbf{X})$, from Ref. [18], 318.15 K (ם). (d) Plots of VLE (O) and LLE (O) Ref. [16].

those appearing in Eq. (8). The most generalized polynomial form can have the following formulation:

$g_{i}(p, T)=g_{i 1}+g_{i 2} p^{2}+g_{i 3} p T+\frac{g_{i 4}}{T}+g_{i 5} T^{2}+g_{i 6} T^{3}$

That is useful to carry out simultaneous correlations of isobaric and isothermal VLE data [40,41], and also of other mixing properties, $h^{\mathrm{E}}$ and $v^{\mathrm{E}}$, with excellent results. With an even more simplified form, the model was used for the correlation of LLE data [43] alone. However, since in this work data were available in the literature for several properties of the same system, and also for LLE, we decided to try to carry out global correlations of all the quantities found for each binary system. Because of the presence in the literature of very variable conditions of pressure and temperature, it was necessary to increase the number of terms in Eq. (16), with a cubic term in $T$. In a previous paper [40], a more reduced form of Eq. (16) was used (containing five terms), however the need for an additional coefficient in this work can be justified by the large temperature range that the model intends to cover, for one system, from the boiling points of the VLE to values of UCST of the LLE, in some cases even lower than $220 \mathrm{~K}$.

The proposed correlation procedure presents an additional difficulty if we compare it with others described in previous works $[42,43]$ since the modeling of LLE with the function $g^{\mathrm{E}}=g^{\mathrm{E}}\left(x_{1}, p\right.$, $T$ ) cannot be carried out directly, since experimental values for $g^{\mathrm{E}}$ are not available for these equilibria. Hence, the combined correlation is carried out by setting up a two-stage procedure, with the following operational aspects:

I. - Initially it would only use the LLE data and would have the goal of trying to improve the fit of the model, using a similar, but tailor-made version of Eq. (1), such as:

$g_{\mathrm{LLE}}^{\mathrm{E}}=z(1-z) \sum_{i=0}^{2} \hat{g}_{i} z^{i}$ 

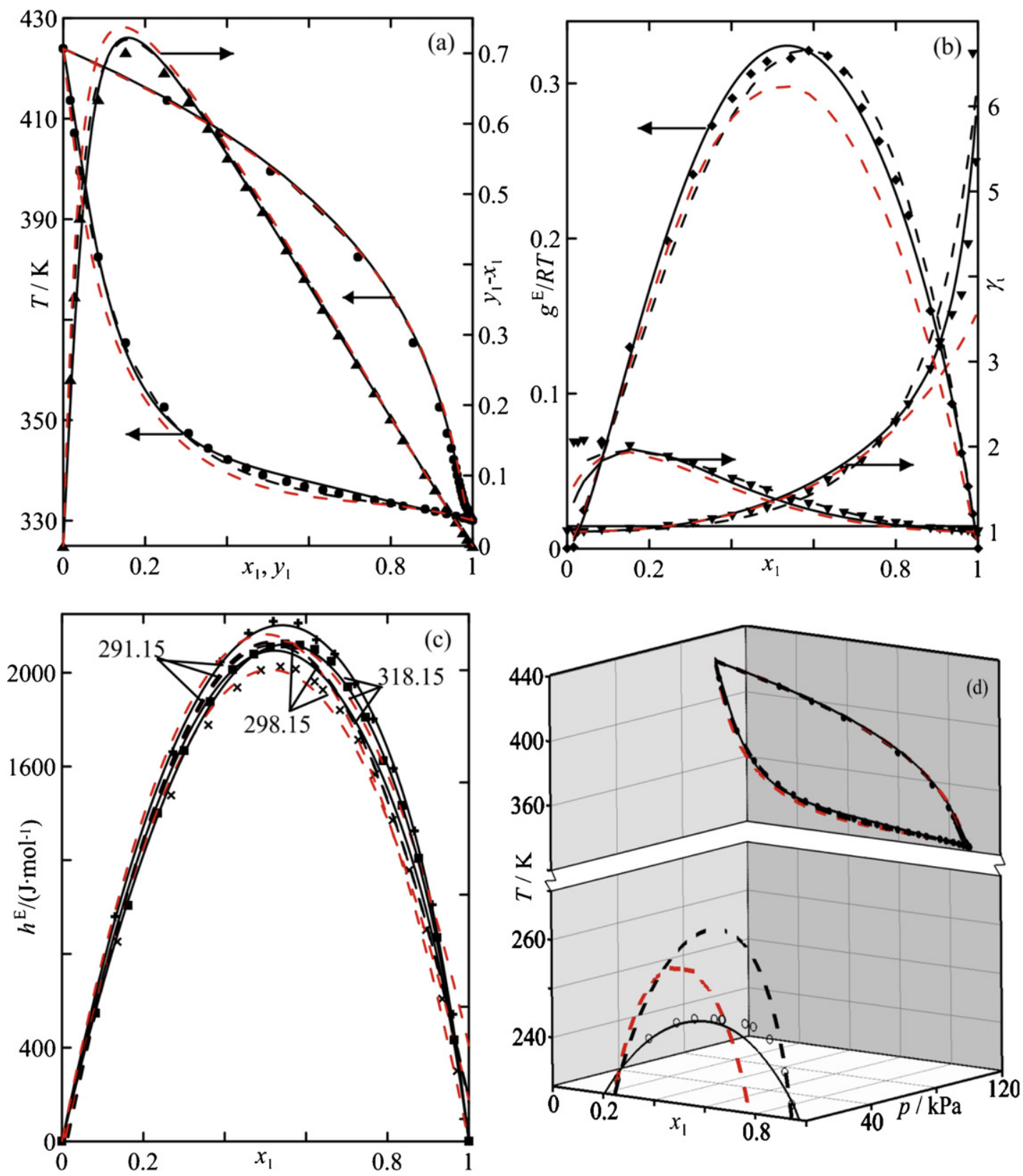

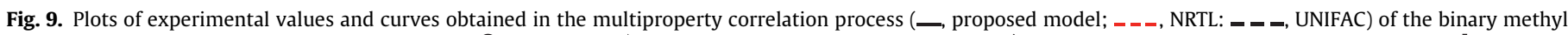

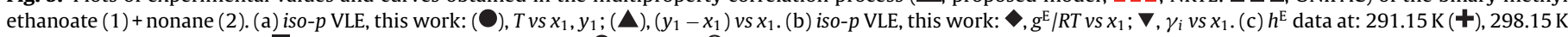
(X), from Ref. [21], 318.15 K ( $\square$ ), from Ref. [23]. (d) Plots of VLE (O) and LLE (O) Ref. [16].

where now the $\hat{g}_{i}$ are the coefficients that generate Gibbs function $g_{\mathrm{ELL}}^{\mathrm{E}}$ for LLE, with a similar expression to Eq. (16) as mentioned previously, but only for the correlation of LLE data.

$\hat{g}_{i}=\hat{g}_{i 1}+\hat{g}_{i 2} p^{2}+\hat{g}_{i 3} p T+\frac{\hat{g}_{i 4}}{T}+\hat{g}_{i 5} T^{2}+\hat{g}_{i 6} T^{3}$

The LLE data taken from the literature for five systems were measured at a single vacuum pressure, so in Eq. (18) only the temperature is affected. However, the methyl ethanoate + heptane system offers values at two pressures, and the complexity of the model increases to fit the data. Since the values corresponding to both parts of Eq. (17) are not known and the data cannot be fitted in the conventional way, it is necessary to recur to a procedure described previously [43]. The isoactivity criterion establishes a necessary condition for the LLE data of the two compounds, generating the following relationships for the activity coefficients

$$
\left.\begin{array}{l}
x_{1 j}^{\mathrm{I}} \gamma_{1}^{\mathrm{I}}\left(x_{1 j}^{\mathrm{I}}, p_{j}, T_{j}\right)=x_{1 j}^{\mathrm{II}} \gamma_{1}^{\mathrm{II}}\left(x_{1 j}^{\mathrm{II}}, p_{j}, T_{j}\right) \\
x_{2 j}^{\mathrm{I}} \gamma_{2}^{\mathrm{I}}\left(x_{1 j}^{\mathrm{I}}, p_{j}, T_{j}\right)=x_{2 j}^{\mathrm{II}} \gamma_{2}^{\mathrm{II}}\left(x_{1 j}^{\mathrm{II}}, p_{j}, T_{j}\right)
\end{array}\right\}
$$

However, these equations are not a sufficient-condition since there are multiple combinations of the parameters $\hat{g}_{i}$ that can satisfy it with some degree of error. It is, therefore, necessary to impose two conditions on the correlation procedure: (a) an objective function that takes into consideration the experimental data and (b) the guarantee of stability of the phases. To be able to carry out this procedure, since the experimental LLE data do not include the compositions of both phases for each temperature, the conjugated compositions must be obtained, for the phase of unknown composition, by interpolation. Now, a first approach is attempted to 

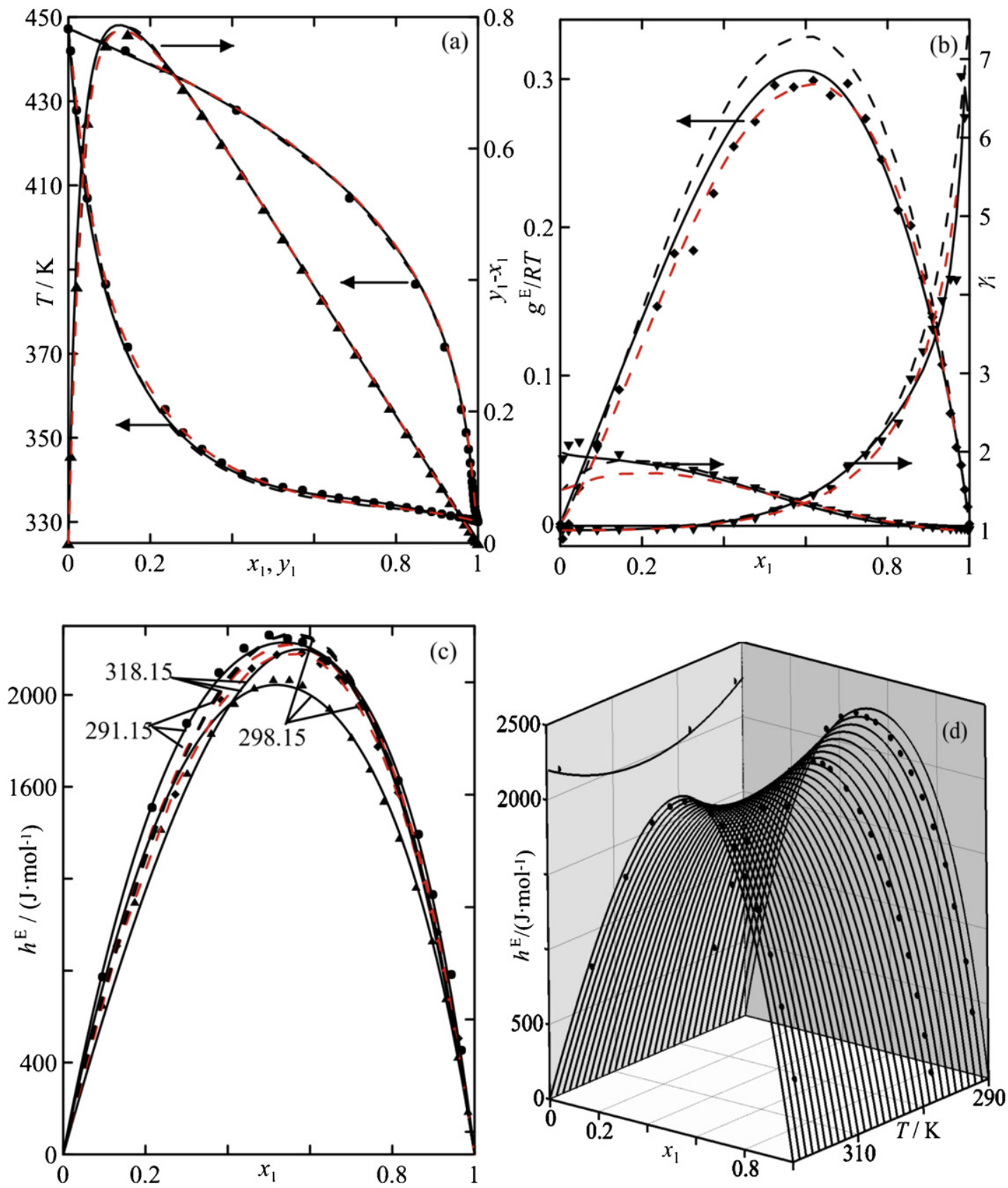

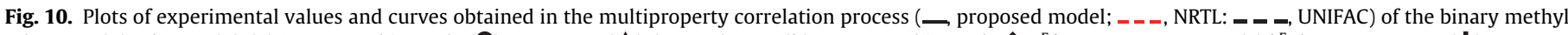

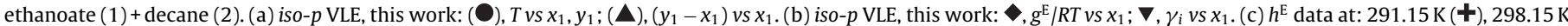
$(\mathbf{X})$, from Ref. [20], 318.15 K ( $\square$ ). (d) Plots in 3D of the surface $h^{\mathrm{E}}\left(x_{1}, T\right)$ resulting of the multiproperty correlation for methyl ethanoate (1) + decane (2).

obtain the activity coefficients, using only the isoactivity criterion through the following objective function:

$(\mathrm{OF})_{\gamma}=\sum_{j=1}^{m} \sum_{i=2}^{2}\left[x_{i j}^{\mathrm{I}} \gamma_{i j}^{\mathrm{I}}\left(x_{i j}^{\mathrm{I}}, T_{j}, p\right)-x_{i j}^{\mathrm{II}} \gamma_{i j}^{\mathrm{II}}\left(x_{i j}^{\mathrm{II}}, T_{j}, p\right)\right]^{2}$

by using the experimental data and also those obtained by interpolation as shown here. In this way, the optimization procedure targets the solution as close as possible to the physical reality. The purpose of this step is to obtain the optimum value of fit of the experimental data, recurring to the following objective function

$(\mathrm{OF})_{x}=\sum_{j=1}^{m} \sum_{i=2}^{2}\left[\left(x_{i j, \exp }^{\mathrm{I}}-x_{i j, \mathrm{cal}}^{\mathrm{I}}\right)-\left(x_{i j, \exp }^{\mathrm{II}}-x_{i j, \mathrm{cal}}^{\mathrm{II}}\right)\right]$
The values of $x_{i j, \text { cal }}^{\mathrm{I}}$ and $x_{i j, \text { cal }}^{\mathrm{II}}$ are obtained by resolving, for a given value of the $\hat{g}_{i}$ parameters, the non-linear system of equations generated by the isoactivity criteria, Eqs. (19). Another aspect to take into consideration at this stage of the calculation is the condition that guarantees the stability of the phases, which is verified with the criterion of the second derivative of Gibbs excess function

$$
\left(\frac{\partial^{2} g_{\mathrm{LLE}}^{\mathrm{E}}}{\partial x_{1}^{2}}\right)+\frac{1}{x_{1} x_{2}}>0
$$

In this stage of the procedure, the set of parameters $\hat{g}_{i}$ is calculated, which generates values for the function defined by Eq. (17), as the most adequate to describe the LLE. 
II. - The final step of the multiproperty regression calculation consists in using Eqs. (7) and (16) but considering in this case a new set of variables (additional to those of iso- $p$ and iso-T VLE, $h^{\mathrm{E}}$, $v^{\mathrm{E}}, c_{\mathrm{p}}^{\mathrm{E}}$ ) provided by the function $g_{\mathrm{LLE}}^{\mathrm{E}}$, according to Eq. (17). This last equation, with the parameters defined by Eq. (18), participates in an intermediate calculus in order to get the values of $g_{\mathrm{LLE}}^{\mathrm{E}}$.

For methyl ethanoate + decane system (without LLE data) the expression used for $g_{i}(p, T)$ was a reduced form of Eq. (16). Hence, the multiobjective function used here is as follows:

$$
\mathrm{OF}=c_{\mathrm{LLE}} s\left(g_{\mathrm{LLE}}^{\mathrm{E}}\right)+c_{\mathrm{VLE}} s\left(g_{\mathrm{VLE}}^{\mathrm{E}}\right)+c_{\mathrm{H}} s\left(h^{\mathrm{E}}\right)+c_{\mathrm{C}} s\left(c_{\mathrm{p}}^{\mathrm{E}}\right)+c_{\mathrm{V}} s\left(v^{\mathrm{E}}\right)
$$

where the $s\left(y^{\mathrm{E}}\right)$ indicate the corresponding standard deviations between the values of the model and the property $y^{\mathrm{E}}$. The coefficients " $c$ " are correction-parameters for the different quantities, which permit these to be modulated to obtain the best value from among the values of the Pareto frontier. Evidently, if data are not available for a given property, its associated coefficient will be zero. The physical values of the $\operatorname{LLE}\left(T, x_{i j, \text { cal }}^{\mathrm{I}}, x_{i j, \text { cal }}^{\mathrm{II}}\right)$ are very sensitive to changes in $g_{\mathrm{LLE}}^{\mathrm{E}}$ values, so to ensure a correct reproduction of the LLEs, the fit of this property must be prioritized using a high value for the corresponding coefficient $c_{\text {LLE }}$. From the second step, the final values of the parameters $g_{i}$ for Eq. (16) of the proposed model, Eq. (7), give rise to a simultaneous representation of all the properties considered.

\subsection{NRTL model}

The NRTL model [44] is one of the ones most used in the field of the thermodynamics of solutions, so it is used as a reference to validate the application of the proposed model; the procedure is shown in detail in the previous section. The mathematical form:

$$
\frac{g^{\mathrm{E}}}{R T}=x_{1}\left(1-x_{1}\right)\left[\frac{G_{21} \tau_{21}}{x_{1}+\left(1-x_{1}\right) G_{21}}+\frac{G_{12} \tau_{12}}{\left(1-x_{1}\right)+x_{1} G_{12}}\right]
$$

contains two adjustable parameters, $G_{i j}$ and $\tau_{i j}$, although both of these are linked together through a third parameter $\alpha$, that gives it non-randomness, $G_{i j}=\exp \left[-\alpha \tau_{i j}(T)\right]$, that can also be subjected to the correlation process described in Section 4.1. However, there are some limitations to application of the NRTL model in the data treatment, mainly because the successive derived functions of Eq. (24) are increasingly complex, making correlation difficult. Because of the complexity of the correlations proposed here, it is necessary to use a model with a greater number of parameters, resorting to more extensive forms for the $\tau_{i j}(T)$. Various options were possible from the literature consulted $[45,46]$ but we chose the one proposed by Ko et al. [47], to which a final summand has been added, which is finally expressed as follows:

$\tau_{i j}=\Delta g_{i j 1}+\frac{\Delta g_{i j 2}}{T}+\Delta g_{i j 3} \ln T+\Delta g_{i j 4} T$

There are nine optimizable parameters of the model, eight $\Delta g_{i j k}$ and $\alpha$. To obtain them, a two-step correlative procedure was used that is described in Section 4.1. First, a function is generated for $\left(g_{\mathrm{LLE}}^{\mathrm{E}} / R T\right)$, which is identified with Eq. (24), from where some values for $\hat{\tau}_{i j}$ and $\hat{G}_{i j}$ are determined, with the limitation of the isoactivity criterion of Eq. (19). In the second step, the theoretical values obtained for this excess Gibbs pseudo-function are used that will later be employed in a multiobjective procedure which includes all the properties available for each system, Eq. (23).

The NRTL model used does not contain terms dependent on pressure, and its capacity is limited to reproduce systems with LLE and VLE data at different values of constant pressure, so cannot be used for the correlation of excess volumes using VLE data in isothermal conditions.

\section{Modeling of thermodynamic data for systems of methyl ethanoate + alkanes}

The procedure indicated in Section 4, both for the proposed model with Eq. (7) and for the NRTL, Eq. (24), was used to correlate the sets of experimental data studied in this work and those presented in the literature for different properties of a given system. The model was practically applied to six binary systems $\left\{\mathrm{CH}_{3} \mathrm{COOCH}_{3}(1)+\mathrm{C}_{n} \mathrm{H}_{2 n+2}(2)(n=5-10)\right\}$. Although our experimentation was the same in the six systems, the availability of the data found in the literature for each one was not uniform, therefore, details of the modeling carried out are given in this section with an independent analysis for each of the binary systems. Table 1 gives a summary of the database used for the treatment and modeling of the mixtures, while Table 6 records the coefficients for the two models used, together with the goodness of fit for each case.

\subsection{Methyl ethanoate + pentane}

The properties used for the modeling of each system were taken from the references shown in Table 1 . Fig. 5b shows the quantities corresponding to adimensional Gibbs function $g^{\mathrm{E}} / R T$, and the activity coefficients $\gamma_{i}$, obtained in the isobaric (this work) and isothermal VLE $[14,15]$. The representation with the proposed model, Eq. (7), can be considered to be acceptable for the different cases of VLE except for those presented in ref [14], which show much higher values than those calculated. Representation of the mixing properties $h^{\mathrm{E}}$ and $v^{\mathrm{E}}$ are acceptable, see Fig. 5c, and show the variation in $h^{\mathrm{E}}=h^{\mathrm{E}}(T)$, which has a negative slope. The correlation is also good for the LLE in spite of the large difference in the working pressure $(0.3 \mathrm{kPa})$ compared to the value of $101.32 \mathrm{kPa}$ for the VLE, which is also clearly reflected in Fig. 5d in 3D.

The multiproperty correlation with the NRTL model [44] can be considered to be acceptable in cases of iso- $p$ and iso- $T$ VLE (see Fig. 5b) although it does not adequately represent the LLE curve (Fig. 5d). The $h^{\mathrm{E}}$ have also been estimated, in spite of the inversion produced in the excess property by the rise in temperature, but the $v^{\mathrm{E}}$ could not be estimated because the equation used does not have terms that include pressure. Finally, the prediction made with the UNIFAC model [39] is acceptable for the VLE, although it is not good at distinguishing the influence of temperature on the enthalpies, since the data $h^{\mathrm{E}}(298 \mathrm{~K})>h^{\mathrm{E}}(291 \mathrm{~K})$ evolve in an opposite direction to the real situation; no deductions can be made about estimation of $v^{\mathrm{E}}$ values either. Fig. $5 \mathrm{a}$ and $\mathrm{b}$ shows a good estimation of VLE data, but not of the system's solubility curve, as can be seen in Fig. 5d.

In summary, the polynomial model proposed here gives a good correlation of all the properties found for the methyl ethanoate + pentane system. The NRTL and UNIFAC adequately predict the VLE (iso- $p$, iso- $T$ ), but not the LLE; the group contribution method does not represent the inversion of the enthalpiestemperature slope either.

\subsection{Methyl ethanoate + hexane}

Table 1 shows the set of data used to model this binary system. Here, the LLE data are shown at $0.4 \mathrm{kPa}$ and only the iso- $p$ VLE data are used, presented in Table S4 (SI), since no others were found in the literature. The polynomial model of the active fractions $z$ produce acceptable estimates in all cases, including the mixing property $h^{\mathrm{E}}$; for this system there is no correlation of the $v^{\mathrm{E}}$ as no iso-T VLE data are available. All this is shown in Fig. $6 \mathrm{a}-\mathrm{d}$, and $3 \mathrm{D}$, of Fig. 6d, represents graphically the quality of fit of the different models for the phase equilibria. Observations about the NRTL are very similar to those made for the methyl ethanoate + pentane mixture, since they do not reproduce the LLE, and show a very similar representation to that produced by the UNIFAC method. This 
Table 6

Results obtained in the multiproperty correlation process using the proposed model and that of NRTL for methyl ethanoate + an alkane.

\begin{tabular}{|c|c|c|c|c|c|c|c|c|c|c|c|}
\hline \multicolumn{7}{|c|}{ Proposed model in this work, Eq. (7) with parameters $g_{i}$ for Eq. (16) } & \multicolumn{5}{|c|}{ NRTL, Eqs. (24) and (25) } \\
\hline$i=$ & $g_{i 1}$ & $g_{i 2}$ & $g_{i 3}$ & $g_{i 4}$ & $g_{i 5}$ & $g_{i 6}$ & $i=$ & 1 & 2 & 3 & 4 \\
\hline \multicolumn{12}{|c|}{ Methyl ethanoate + pentane } \\
\hline 0 & $1.103 \mathrm{E} 4$ & $-2.200 \mathrm{E}-4$ & $1.644 \mathrm{E}-4$ & $-6.190 \mathrm{E}+5$ & $-9.686 \mathrm{E}-2$ & $1.285 \mathrm{E}-4$ & $a_{12 i}$ & $1.965 \mathrm{E}+3$ & $1.054 \mathrm{E}+5$ & $-2.454 \mathrm{E}+2$ & 2.069 \\
\hline 1 & $2.866 \mathrm{E} 4$ & $7.474 \mathrm{E}-4$ & $-5.195 \mathrm{E}-4$ & $-4.608 \mathrm{E}+6$ & $-3.568 \mathrm{E}-1$ & $6.667 \mathrm{E}-4$ & $a_{21 i}$ & $1.055 \mathrm{E}+2$ & $-1.534 \mathrm{E}+5$ & $-1.236 \mathrm{E}+2$ & -1.378 \\
\hline \multirow[t]{2}{*}{2} & $3.475 \mathrm{E} 4$ & $-5.614 \mathrm{E}-4$ & $4.016 \mathrm{E}-4$ & $-3.272 \mathrm{E}+6$ & $-6.498 \mathrm{E}-1$ & $1.317 \mathrm{E}-3$ & & & & & \\
\hline & $k_{\mathrm{g}}=1.000$ & $k_{\mathrm{h}}=1.394$ & $k_{\mathrm{V}}=0.362$ & & & & & & $\alpha=4.98 \mathrm{E}-6$ & & \\
\hline$s\left(g^{\mathrm{E}} / R T\right)$ & & & 0.031 & & & & & & 0.033 & & \\
\hline$s\left(\gamma_{i}\right)$ & & & 0.401 & & & & & & 0.479 & & \\
\hline$s\left(h^{\mathrm{E}}\right)$ & & & 114 & & & & & & 108 & & \\
\hline$s\left(v^{\mathrm{E}}\right)$ & & & 55 & & & & & & & & \\
\hline$s\left(c_{\mathrm{p}}^{\mathrm{E}}\right)$ & & & - & & & & & & & & \\
\hline$s\left(x_{\mathrm{ELL}}\right)$ & & & 0.069 & & & & & & & & \\
\hline \multicolumn{12}{|c|}{ Methyl ethanoate + hexane } \\
\hline 0 & $-6.201 \mathrm{E} 4$ & 1.037 & $-3.926 \mathrm{E}-1$ & $9.398 \mathrm{E}+6$ & $7.370 \mathrm{E}-1$ & $-1.147 \mathrm{E}-3$ & $a_{12 i}$ & $4.859 \mathrm{E} 1$ & $-2.050 \mathrm{E} 4$ & $1.205 \mathrm{E} 1$ & $-1.859 \mathrm{E}-1$ \\
\hline 1 & $-8.889 \mathrm{E} 4$ & 1.463 & $-5.887 \mathrm{E}-1$ & $1.207 \mathrm{E}+7$ & 1.060 & $-1.640 \mathrm{E}-3$ & $a_{21 i}$ & $-2.550 \mathrm{E} 1$ & $1.505 \mathrm{E} 4$ & -9.660 & $1.267 \mathrm{E}-1$ \\
\hline \multirow[t]{2}{*}{2} & $-1.164 \mathrm{E} 5$ & 2.014 & $-8.049 \mathrm{E}-1$ & $1.606 \mathrm{E}+7$ & 1.397 & $-2.122 \mathrm{E}-3$ & & & & & \\
\hline & $k_{\mathrm{g}}=0.909$ & $k_{\mathrm{h}}=1.084$ & & & & & & & $\alpha=-1.12 \mathrm{E}-2$ & & \\
\hline$s\left(g^{\mathrm{E}} / R T\right)$ & & & 0.006 & & & & & & 0.010 & & \\
\hline$s\left(\gamma_{i}\right)$ & & & 0.080 & & & & & & 0.225 & & \\
\hline$s\left(h^{\mathrm{E}}\right)$ & & & 100 & & & & & & 109 & & \\
\hline \multicolumn{12}{|l|}{$s\left(v^{\mathrm{E}}\right)$} \\
\hline \multicolumn{12}{|l|}{$s\left(c_{\mathrm{p}}^{\mathrm{E}}\right)$} \\
\hline$s\left(x_{\mathrm{ELL}}\right)$ & & & 0.0141 & & & & & & 0.032 & & \\
\hline \multicolumn{12}{|c|}{ Methyl ethanoate + heptane } \\
\hline $\mathrm{i}=$ & $g_{i 1}$ & $g_{i 2}$ & $g_{i 3}$ & $g_{i 4}$ & $g_{i 5}$ & $g_{i 6}$ & $\mathrm{i}=$ & 1 & 2 & 3 & 4 \\
\hline 0 & $-6.141 \mathrm{E} 3$ & $5.141 \mathrm{E}-1$ & $-1.663 \mathrm{E}-1$ & $1.913 \mathrm{E} 6$ & $9.668 \mathrm{E}-2$ & $-1.726 \mathrm{E}-4$ & $a_{12 i}$ & $8.314 \mathrm{E} 1$ & $-2.271 \mathrm{E} 4$ & $2.734 \mathrm{E} 1$ & $-2.432 \mathrm{E}-1$ \\
\hline 1 & $8.306 \mathrm{E} 2$ & -1.491 & $4.888 \mathrm{E}-1$ & $-6.437 \mathrm{E} 5$ & $6.584 \mathrm{E}-3$ & $-6.677 \mathrm{E}-5$ & $a_{21 i}$ & $-6.995 \mathrm{E} 1$ & $2.159 \mathrm{E} 4$ & $-2.734 \mathrm{E} 1$ & $2.286 \mathrm{E}-1$ \\
\hline 2 & $-2.829 \mathrm{E} 3$ & 1.169 & $-3.847 \mathrm{E}-1$ & $7.089 \mathrm{E} 5$ & $2.561 \mathrm{E}-2$ & $1.976 \mathrm{E}-5$ & & & & & \\
\hline & $k_{\mathrm{g}}=1.156$ & $k_{\mathrm{h}}=1.572$ & - & $k_{\mathrm{C}}=1.232$ & & & & & $\alpha=4.67 \mathrm{E}-4$ & & \\
\hline$s\left(g^{\mathrm{E}} / R T\right)$ & & & 0.006 & & & & & & 0.007 & & \\
\hline$s\left(\gamma_{\mathrm{i}}\right)$ & & & 0.099 & & & & & & 0.368 & & \\
\hline$s\left(h^{\mathrm{E}}\right)$ & & & 268 & & & & & & 323 & & \\
\hline$s\left(v^{\mathrm{E}}\right)$ & & & & & & & & & & & \\
\hline$s\left(c_{\mathrm{p}}^{\mathrm{E}}\right)$ & & & 0.02 & & & & & & 0.2 & & \\
\hline$s\left(x_{\mathrm{ELL}}\right)$ & & & 0.114 & & & & & & 0.446 & & \\
\hline Methyl et & noate + octa & & & & & & & & & & \\
\hline 0 & $-4.424 \mathrm{E} 4$ & 2.224 & $-8.944 \mathrm{E}-1$ & $6.210 \mathrm{E} 6$ & $6.282 \mathrm{E}-1$ & $-8.573 \mathrm{E}-4$ & $a_{12 i}$ & $9.351 \mathrm{E} 4$ & $5.249 \mathrm{E} 6$ & $1.287 \mathrm{E} 4$ & $2.060 \mathrm{E} 2$ \\
\hline 1 & $-1.761 \mathrm{E} 5$ & -6.456 & 2.811 & $3.078 \mathrm{E} 7$ & 1.454 & $-2.990 \mathrm{E}-3$ & $a_{21 i}$ & $1.316 \mathrm{E} 1$ & $1.648 \mathrm{E} 2$ & -2.112 & $-9.700 \mathrm{E}-4$ \\
\hline 2 & $-8.144 \mathrm{E} 4$ & $1.084 \mathrm{E} 1$ & -4.557 & $4.008 \mathrm{E} 6$ & 1.588 & $-1.687 \mathrm{E}-3$ & & & & & \\
\hline & $k_{\mathrm{g}}=1.650$ & $k_{\mathrm{h}}=1.278$ & & & & & & & $\alpha=6.48 \mathrm{E}-5$ & & \\
\hline$s\left(g^{\mathrm{E}} / R T\right)$ & & & 0.021 & & & & & & 0.027 & & \\
\hline$s\left(\gamma_{i}\right)$ & & & 0.093 & & & & & & 0.830 & & \\
\hline$s\left(h^{\mathrm{E}}\right)$ & & & 45 & & & & & & 317 & & \\
\hline$s\left(v^{\mathrm{E}}\right)$ & & & - & & & & & & & & \\
\hline$s\left(c_{\mathrm{p}}^{\mathrm{E}}\right)$ & & & - & & & & & & & & \\
\hline$s\left(x_{\mathrm{ELL}}\right)$ & & & 0.025 & & & & & & 0.046 & & \\
\hline Methyl et & noate + non & & & & & & & & & & \\
\hline 0 & $-8.661 \mathrm{E} 4$ & $4.516 \mathrm{E}-1$ & $-6.561 \mathrm{E}-2$ & $1.470 \mathrm{E} 7$ & $9.067 \mathrm{E}-1$ & $-1.467 \mathrm{E}-3$ & $a_{12 i}$ & $-3.118 \mathrm{E} 5$ & $4.572 \mathrm{E} 7$ & $-3.516 \mathrm{E} 3$ & $6.194 \mathrm{E} 2$ \\
\hline 1 & $-1.226 \mathrm{E} 5$ & 1.043 & $-6.018 \mathrm{E}-1$ & $1.469 \mathrm{E} 7$ & 1.580 & $-2.569 \mathrm{E}-3$ & $a_{21 i}$ & $7.109 \mathrm{E} 1$ & $-1.872 \mathrm{E} 3$ & $-1.147 \mathrm{E} 1$ & $7.240 \mathrm{E}-3$ \\
\hline 2 & $-1.057 \mathrm{E} 5$ & 2.176 & $-7.355 \mathrm{E}-1$ & $1.603 \mathrm{E} 7$ & 1.111 & $-1.604 \mathrm{E}-3$ & & & & & \\
\hline & $k_{\mathrm{g}}=1.839$ & $k_{\mathrm{h}}=1.847$ & & & & & & & $\alpha=2.47 \mathrm{E}-3$ & & \\
\hline$s\left(g^{\mathrm{E}} / R T\right)$ & & & 0.006 & & & & & & 0.022 & & \\
\hline$s\left(\gamma_{\mathrm{i}}\right)$ & & & 0.514 & & & & & & 0.937 & & \\
\hline$s\left(h^{\mathrm{E}}\right)$ & & & 61 & & & & & & 349 & & \\
\hline$s\left(v^{\mathrm{E}}\right)$ & & & - & & & & & & & & \\
\hline$s\left(c_{\mathrm{p}}^{\mathrm{E}}\right)$ & & & - & & & & & & & & \\
\hline$s\left(x_{\mathrm{ELL}}\right)$ & & & 0.078 & & & & & & 0.092 & & \\
\hline Methyl et & noate + deca & & & & & & & & & & \\
\hline 0 & $-7.178 \mathrm{E} 4$ & $-8.142 \mathrm{E}-1$ & 2.066 & $1.152 \mathrm{E} 7$ & $-1.590 \mathrm{E}-1$ & - & $a_{12 i}$ & $1.113 \mathrm{E} 1$ & $-3.197 \mathrm{E} 2$ & -1.484 & -4.736 \\
\hline 1 & $-5.084 \mathrm{E} 5$ & -5.954 & $2.073 \mathrm{E} 1$ & $4.914 \mathrm{E} 7$ & -2.587 & - & $a_{21 i}$ & $1.757 \mathrm{E} 2$ & -1.670 & $4.861 \mathrm{E}-3$ & $7.113 \mathrm{E}-3$ \\
\hline 2 & $-2.771 \mathrm{E} 5$ & $-1.968 \mathrm{E} 1$ & 1.350E1 & $5.587 \mathrm{E} 7$ & -1.258 & - & & & & & \\
\hline & $k_{\mathrm{g}}=2.872$ & $k_{\mathrm{h}}=1.307$ & & & & & & & $\alpha=-8.81 \mathrm{E}-1$ & & \\
\hline$s\left(g^{\mathrm{E}} / R T\right)$ & & & 0.012 & & & & & & 0.007 & & \\
\hline$s\left(\gamma_{\mathrm{i}}\right)$ & & & 0.330 & & & & & & 0.505 & & \\
\hline$s\left(h^{\mathrm{E}}\right)$ & & & 131 & & & & & & 245 & & \\
\hline$s\left(v^{\mathrm{E}}\right)$ & & & - & & & & & & & & \\
\hline$s\left(c_{\mathrm{p}}^{\mathrm{E}}\right)$ & & & - & & & & & & & & \\
\hline
\end{tabular}


latter does not reproduce the variation in the $h^{\mathrm{E}}=h^{\mathrm{E}}(T)$ slope that is reflected by the proposed model. In this and the following mixtures, the model presents a maximum in the representations of $\gamma_{i}$, and these are not always reflected by experimental values; the maximum is very pronounced in this case (see Fig. 6b).

\subsection{Methyl ethanoate + heptane}

For the methyl ethanoate + heptane system experimental data of isobaric VLE have been taken, shown in Table S4 (SI), and $h^{\mathrm{E}}$ data at several temperatures from the references recorded in Table 1 . Moreover, this is the only binary for which $c_{\mathrm{p}}^{\mathrm{E}}$ [29] data are available, which can be used to define the profile of the function $h^{\mathrm{E}}=h^{\mathrm{E}}(x, T)$, this must therefore present a minimum in the interval [291.15-298.15] K, a single point where it is found that $\left(\partial h^{\mathrm{E}} / \partial T\right)_{\mathrm{p}}=c_{\mathrm{p}}^{\mathrm{E}}=0$, previously mentioned in Section 3.1, which results in the representation of a hyperbolic paraboloid like the one shown in Fig. 1a. Moreover, for this system the literature consulted $[16,17]$ presents two series of LLE data, one measured in a high vac$\operatorname{uum}(0.7 \mathrm{kPa})$ and the other series measured almost at atmospheric pressure, for which the references are given in Table 1 . The combination of all these properties comprises a database that makes it difficult to carry out the mathematical modeling.

For this system, our model carries out a combined correlation of the properties mentioned, which can be qualified as good. The parameters of fit obtained and the standard deviations of each property are recorded in detail in Table 6 and the corresponding representations of these are shown in Fig. 7a-f. The recalculated values of $\left(T, x_{1}, y_{1}\right)$ shown in Fig. 7a are in good agreement with experimental values, while the LLE at $0.7 \mathrm{kPa}$ are reproduced adequately, although with a slight increase in the UCST value. By contrast, the LLE curve obtained at $82 \mathrm{kPa}$ is somewhat lower than that measured by Riccardi et al. [17]. In this case, the model does not give a good representation of the LLE, perhaps because the experimental behavior of the mixture at $82 \mathrm{kPa}$ is opposite to what one would expect when referring to the other case, see Ref. [16] (the increase in pressure usually would correspond to a decrease in the UCST); which would result in an undesired representation. Finally, Fig. 7d shows the good estimation of the $c_{\mathrm{p}}^{\mathrm{E}}$ curve that produces two "singular points" close to $x_{1}=0.28$ and $x_{1}=0.89$ where $c_{\mathrm{p}}^{\mathrm{E}}=0$. Fig. $7 \mathrm{f}$ shows the $3 \mathrm{D}$ representation of the hyperbolic paraboloid that the proposed model produces in its multiproperty correlation, together with other quantities considered for this system. In this case, there is a loss of precision owing to the extensive correlative capacity required of the model.

When the NRTL is used, it is noteworthy that the model does not distinguish the measurements made at different pressures and provides the same fit of LLE data (see Fig. 7e) producing an overdimensioned curve for $T$ in relation to experimental data. Fig. 7c shows the results of fitting the $h^{\mathrm{E}}$, in which the NRTL model is incapable of correlating the enthalpies at different $T$, producing curves that are very close together, giving rise to an inadequate representation of $c_{\mathrm{p}}^{\mathrm{E}}(x)$ (see Fig. 7d). Finally, the UNIFAC group contribution method gives an acceptable representation of the VLE and the $h^{\mathrm{E}}$ from a qualitative perspective, since the slope with the temperature of $h^{\mathrm{E}}=h^{\mathrm{E}}(T)$ is positive, and does not show the inversion the property produces for this system. Therefore, the heat capacity (Fig. 7d) is positive and is very different from real values. Representation of the LLE for this system is similar to that obtained with the NRTL model, as shown in Fig. 7e.

\subsection{Systems methyl ethanoate + octane and + nonane}

Details of the modeling of the system of methyl ethanoate with octane and with nonane are given here in the same section, since analogous data are available for both systems, as shown in Table 1. The only differences worth noting are a slight difference in the working pressure in LLE measurements of $1.1 \mathrm{kPa}$ for octane and $1.8 \mathrm{kPa}$ for the mixture with nonane. Figs. 8a-d and 9-d show the representations for the corresponding systems made with the polynomial model, Eq. (7), and that of NRTL, Eq. (24), showing a very different correlation of VLE and LLE data for both of these. The greatest differences are found with the NRTL model, which does not represent both equilibria, but this does not happen for the enthalpies. The UNIFAC model produces an acceptable representation of VLE data and enthalpies from a qualitative perspective (without distinguishing working temperatures), but not of LLE, as can be seen in Figs. 8d and 9d.

\subsection{Methyl ethanoate + decane}

LLE data were not found in the literature for this system so the correlation process only uses data produced in this work. Hence, a smaller number of coefficients were used for the model, Eq. (7), and $g_{i 6}$ used in previous cases was eliminated from the model, as can be seen in Eq. (16). With the parameters shown in Table 6, the corresponding representations shown in Fig. 10a-d were produced, showing a good correlation of all the properties; the quantitative assessment is confirmed with the deviations shown in Table 6. The hyperbolic paraboloid representation that shows the surface $h^{\mathrm{E}}=h^{\mathrm{E}}(x, T)$ for this system can be seen in Fig. 10d. Similarly, with the parameters of the NRTL model of the same table, an acceptable representation is obtained of the VLE data (see Fig. 10a and b) although the representation of the $h^{\mathrm{E}}$ is less complete, owing to the difficulty of following the variation with $T$. The UNIFAC method slightly overestimates the VLE properties, although it gives a good representation of the values of $(x, y, T)$, as can be seen in Fig. 10a. As for the remaining systems, the group contribution method does not establish the variations in $h^{\mathrm{E}}=h^{\mathrm{E}}(T)$.

\section{Discussion}

For this work, the authors set an objective based on the multiproperty thermodynamic-mathematical modeling belonging to the same fluid system, using two models: an extended version of the NRTL [44-47] and a polynomial model used previously [40-43]. The objective was to study the capacity of both of these to represent a set of systems for which values of their thermodynamic properties are presented in significantly different working conditions. These were applied to a set of binary systems of methyl ethanoate + alkanes $\left(C_{5}-C_{10}\right)$ and experimental data of the mixing properties, $v^{\mathrm{E}}$ and $h^{\mathrm{E}}$, were provided at different temperatures and isobaric VLE at $101.32 \mathrm{kPa}$. Data of other properties were obtained from the literature: $c_{\mathrm{p}}^{\mathrm{E}}$ for the methyl ethanoate + heptane mixture [29], iso-T VLEs for methyl ethanoate + pentane [14,15], and LLEs at low pressures for all the mixtures $[16,17]$ except for decane. The resulting database is recorded in Table 1 . The summary of the application of the model for a multiproperty correlation for the systems chosen is that the proposed polynomial model, Eq. (7), with the coefficients $g_{i}=g_{i}(T, p)$ expressed by a similar equation to Eq. (17), reproduces well the general behavior of the selected binary systems through their different properties. Application of the NRTL model to the same cases gives an acceptable representation of VLE and enthalpies but not of LLE or the $c_{\mathrm{p}}^{\mathrm{E}}$ of the only system studied; NRTL alone does not give values of $v^{\mathrm{E}}$. The parameter $\alpha$ obtained in this work for the different mixtures (see Table 6) is almost zero except for the one corresponding to the mixture with decane. However, this parameter must not be omitted or nulled because then Eq. (25) would be changed from the initial form. The polynomial model has the advantage of being flexible, permitting the number of 
parameters to be changed and the number of coefficients to be optimized to suit different situations. Properties have also been estimated with UNIFAC, version of Gmehling et al. [39], which, with the same set of parameters exclusive for the interaction $\mathrm{CH}_{3} \mathrm{COO} / \mathrm{CH}_{2}$, presents a similar behavior to the NRTL model, both in the estimation of isothermal and isobaric VLE, which it does acceptably, and also in the estimation of LLE and $c_{\mathrm{p}}^{\mathrm{E}}$ for which its description is not correct.

Future works will aim to extend the model to systems with a broader database, in an attempt to reproduce part of the surface representing the pressure-temperature-composition of a given system (Fig. 1b) to improve the correlative capacity of the proposed model for multiproperties.

\section{List of symbols}

$A, B, C$ Antoine constants

$a, b, c \quad$ constants for Antoine equation in reduced form

$A_{i j} \quad$ coefficients of Eq. (2)

$a_{i} \quad$ coefficients of Eq. (1)

$B_{i i} \quad$ second virial coefficients for pure component $\mathrm{i}$

$B_{i j} \quad$ cross second virial coefficients for mixture $i-j$

$c_{\mathrm{p}}^{\mathrm{E}} \quad$ excess thermal molar capacity

$c_{\mathrm{M}} \quad$ correction-coefficients of Eq. (23) for M-property: LLE, VLE, $h^{\mathrm{E}}, c_{\mathrm{p}}^{\mathrm{E}}, v^{\mathrm{E}}$

$G_{i j} \quad$ coefficients of Eq. (8)

$g^{\mathrm{E}} \quad$ excess molar Gibbs function

$g_{i} \quad$ coefficients of Eq. (7)

$\hat{g}_{i} \quad$ particular coefficients for Eq. (18)

$h^{\mathrm{E}} \quad$ excess molar enthalpy

$k \quad$ parameter of Eq. (3)

$n_{\mathrm{D}} \quad$ refractive index

OF objective function

$p \quad$ total pressure

$p_{c} \quad$ critical pressure

$p_{i}^{\mathrm{o}} \quad$ vapor pressure for component $i$

$p_{i, \mathrm{r}}^{\mathrm{o}} \quad$ reduced vapour pressure for component $i$

$q_{i} \quad$ surface parameter for component $i$

$R \quad$ gas constant

$r_{i} \quad$ volume parameter for component $i$

$s^{\mathrm{E}} \quad$ excess molar entropy

$s \quad$ standard deviation

$T \quad$ temperature

$T_{\mathrm{b}, i}^{\mathrm{o}} \quad$ normal boiling temperature for component $i$

$T_{\mathrm{c}} \quad$ critical temperature

$v_{i}^{\text {o }} \quad$ saturated liquid molar volume for component $i$

$v^{\mathrm{E}} \quad$ excess molar volume.

$x_{i} \quad$ molar fraction in the liquid phase for component $i$

$y_{i} \quad$ molar fraction in the vapor phase for component $i$

$Z_{\mathrm{RA}} \quad$ parameter of Rackett equation

$z_{i} \quad$ active fraction for component $i$

\section{Greek letters}

$\gamma_{i} \quad$ activity coefficient of component $i$

$\gamma_{i}^{\infty} \quad$ activity coefficient at infinite dilution of component $i$

$\rho$ density

$\omega \quad$ acentric factor

\section{Acknowledgements}

This work was carried out with financial support from the Spanish MINECO (project CTQ2009-12482). The authors (L.F., E.P., and J.O.) acknowledge the financial support received.

\section{Appendix A. Supplementary data}

Supplementary data associated with this article can be found, in the online version, at http://dx.doi.org/10.1016/j.fluid.2012.12.027.

\section{References}

[1] J. Ortega, J.S. Matos, M.I. Paz, E. Jimenez, J. Chem. Thermodyn. 17 (1985) 1127-1132.

[2] J. Ortega, J.D. García, Can. J. Chem. 66 (1988) 1520-1524.

[3] J. Ortega, J.L. Legido, Fluid Phase Equilib. 95 (1944) 175-214.

[4] J. Ortega, C. Gonzalez, J.A. Peña, S. Galván, Fluid Phase Equilib. 170 (2000) $87-111$.

[5] J. Ortega, S. Galván, J. Chem. Eng. Data 40 (1995) 699-703.

[6] J. Ortega, F. Espiau, G. Sabater, M.A. Postigo, J. Chem. Eng. Data 51 (2006) 730-742.

[7] J. Ortega, P. Susial, J. Chem. Eng. Jpn. 23 (1990) 621-626.

[8] A. Soto, P. Hernández, J. Ortega, Fluid Phase Equilib. 146 (1998) 351-370.

[9] A.M. Blanco, J. Ortega, J. Chem. Eng. Data 43 (1998) 638-645.

[10] J. Ortega, M.A. Postigo, F. Espiau, J. Chem. Eng. Data 49 (2004) 1602-1612.

[11] G. Sabater, J. Ortega, Fluid Phase Equilib. 291 (2010) 18-31.

[12] L. Fernández, E. Perez, J. Ortega, J. Canosa, J. Wisniak, J. Chem. Eng. Data 55 (2010) 5519-5533.

[13] J. Ortega, F. Espiau, J. Tojo, J. Canosa, A. Rodriguez, J. Chem. Eng. Data 48 (2003) 1183-1190.

[14] M.L.G. de Soria, L.L. Zurita, M.A. Postigo, M. Katz, Thermochim. Acta 130 (1988) 249-258.

[15] B.C.-Y. Lu, T. Ishikawa, G.C. Benson, J. Chem. Eng. Data 35 (1990) 331-334.

[16] M. Rolla, P. Franzosini, R. Riccardi, L. Bottelli, Z. Naturforsch. A: Phys. Sci. 96 (1966) 601-603.

[17] R. Riccardi, M. Sanesi, Gazz. Chim. Ital. 96 (1966) 542-551.

[18] J. Ortega, E. Gonzalez, J.S. Matos, J.L. Legido, Chem. Thermodyn. 24 (1992) $15-22$.

[19] E. Gonzalez, J. Ortega, J.S. Matos, G. Tardajos, J. Chem. Thermodyn. 25 (1993) 561-568.

[20] J. Ortega, E. Gonzalez, J. Chem. Thermodyn. 25 (1993) 495-501.

[21] J. Ortega, J.S. Matos, J.A. Peña, Thermochim. Acta 160 (1990) 337-342.

[22] J. Ortega, J.L. Legido, J. Fernández, L. Pías, M.I. Paz, Ber. Bunsenges. Phys. Chem. 95 (1991) 128-135.

[23] J. Ortega, F. Espiau, F.J. Toledo, J. Chem. Thermodyn. 36 (2004) 193-209.

[24] M.A. Postigo, P.H. Garcia, J. Ortega, G. Tardajos, J. Chem. Eng. Data 40 (1995) 283-289.

[25] J. Ortega, J.S. Matos, J.A. Peña, Thermochim. Acta 195 (1992) 321-327.

[26] A. Qin, D.E. Hoffman, P. Munk, J. Chem. Eng. Data 37 (1992) 55-61.

[27] S.L. Oswal, I.N. Patel, Fluid Phase Equilib. 149 (1998) 249-259.

[28] A.M. Awwad, K.A. Jbara, A.H. Al-Dujaili, Thermochim. Acta 129 (1988) 249-262.

[29] M. Pintos, R. Bravo, M.C. Baluja, M.I. Paz, G.R. Desgranges, J.-P.E. Grolier, Can. J Chem. 66 (1988) 1179-1186.

[30] J.S. Matos, J.L. Trenzado, M.N. Caro, E. Romano, E. Perez, J. Chem. Thermodyn. 26 (1994) 857-862.

[31] J.S. Matos, J.L. Trenzado, E. Romano, M.N. Caro, E. Pérez, J. Solution Chem. 30 (2001) 263-279.

[32] N.V. Sastry, R.R. Thakor, M.C. Patel, J. Mol. Liq. 144 (2009) 13-22.

[33] J.-P.E. Grolier, D. Ballet, A. Viallard, J. Chem. Thermodyn. 6 (1974) 895-908.

[34] I. Nagata, M. Nagashima, K. Kazuma, M. Nakagawa, J. Chem. Eng. Jpn. 8 (1975) 261-265.

[35] S. Otin, G. Tomas, J.M. Peiró, I. Velasco, C. Gutierrez-Losa, J. Chem. Thermodyn. 12 (1980) 955-960.

[36] E. Collinet, J. Gmehling, Fluid Phase Equilib. 230 (2005) 131-142.

[37] O. Dusart, S. Piekarski, J.-P.E. Grolier, J. Chim. Phys. Phys. Chim. Biol. 76 (1979) 433-437.

[38] H. Kehlen, R. Hering, Z. Phys. Chem. Leipzig 256 (1975) 778-780.

[39] J. Gmehling, J. Li, M. Schiller, Ind. Eng. Chem. Res. 32 (1993) 178-183.

[40] J. Ortega, F. Espiau, Ind. Eng. Chem. Res. 42 (2003) 4978-4992.

[41] J. Ortega, F. Espiau, R. Vreekamp, J. Tojo, Ind. Eng. Chem. Res. 46 (2007) 7353-7366.

[42] F. Espiau, J. Ortega, E. Penco, J. Wisniak, Ind. Eng. Chem. Res. 49 (2010) 9548-9558.

[43] F. Espiau, J. Ortega, L. Fernández, J. Wisniak, Eng. Chem. Res. 50 (2011) $12259-12270$.

[44] H. Renon, J.M. Prausnitz, AIChE J. 14 (1968) 135-144.

[45] F. Zielke, D.A. Lempe, Fluid Phase Equilib. 141 (1997) 63-85.

[46] J. Connemann, J. Gaube, L. Karrer, A. Pfenning, U. Reuter, Fluid Phase Equilib. 60 (1990) 99-118.

[47] M. Ko, J. Im, J.Y. Sung, H. Kim, J. Chem. Eng. Data 52 (2007) 1464-1467.

[48] J.A. Riddick, W.B. Bunger, T.K. Sakano, Organic solvents: physical properties and methods of purification Techniques of Chemistry, vol. II, 4th ed., WileyInterscience, NY, 1986.

[49] J. Ortega, J.S. Matos, Mater. Chem. Phys. 15 (1986) 415-425. 
[50] TRC, Thermodynamic Tables of Non-Hydrocarbons \& Hydrocarbons, Thermodynamic Research Center, Texas A\&M University System College Station, TX, 1993, Extant 2012.

[51] H.C. Van Ness, M.M. Abott, Int. DATA Ser. Sel. Data Mixtures Ser. A 1 (1976) 22.

[52] J. Ortega, J.A. Peña, C. de Afonso, J. Chem. Eng. Data 31 (1986) 339-342.

[53] A. Bondi, Physical Properties of Molecular Crystals, Liquids and Glasses, Wiley, NY, 1968.

[54] M. Oki, H. Nakanishi, Bull. Chem. Soc. Jpn. 44 (1971) 3144-3147.

[55] K.S. Pitzer, J. Am. Chem. Soc. 77 (1955) 3427-3433.

[56] B.I. Lee, M.G. Kesler, AIChE J. 21 (1975) 510-527.
[57] C.F. Spencer, R.P.J. Danner, Chem. Eng. Data 17 (1972) 236-241.

[58] R.C. Reid, J.M. Prausnitz, B.E. Poiling, The Properties of Gases and Liquids, 4th ed., McGraw Hill, NY, 1988.

[59] C. Tsonopoulos, AIChE J. 24 (1978) 1112-1115.

[60] A. Fredenslund, J. Gmehling, P. Rasmussen, Vapor-Liquid Equilibria Using UNIFAC: A Group Contribution Method, Elsevier, Amsterdam, 1977.

[61] H. Koch, H.G.V. Raay, Brennst. Chem. 35 (1954) 105-112.

[62] L.S. Kudryavtseva, O.G. Eizen, M.P. Susarev, Zh. Fiz. Khim. 40 (1966) 1285-1291.

[63] J. Gmehling, J. Menke, J. Krafczyk, K. Fischer, Azeotropic Data, VCH, Weinheim, Germany, 1994.

[64] A.M. Pivovarov, A.N. Marinichev, M.P. Susarev, Vestin. Lenin. Univ. Fiz. Kh. 1 (1976) 100-105. 